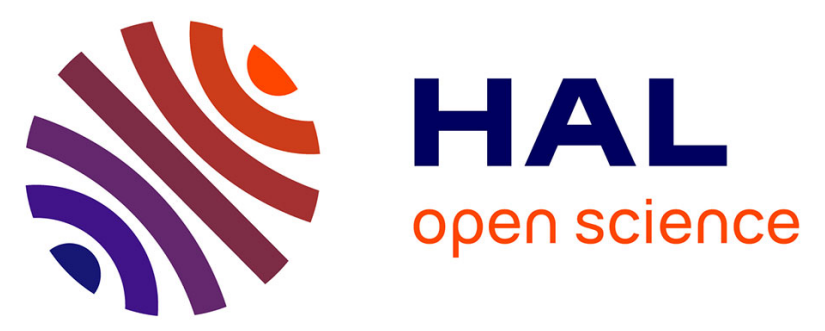

\title{
Hydromechanical interactions in a fractured carbonate reservoir inferred from hydraulic and mechanical measurements
}

\author{
Frédéric Cappa, Yves Guglielmi, Pascal Fénart, Véronique \\ Merrien-Soukatchoff, Alain Thoraval
}

\section{To cite this version:}

Frédéric Cappa, Yves Guglielmi, Pascal Fénart, Véronique Merrien-Soukatchoff, Alain Thoraval. Hydromechanical interactions in a fractured carbonate reservoir inferred from hydraulic and mechanical measurements. International Journal of Rock Mechanics and Mining Sciences, 2004, 42 (2005), pp.287306. ineris-00175357

HAL Id: ineris-00175357

https://hal-ineris.archives-ouvertes.fr/ineris-00175357

Submitted on 1 Oct 2007

HAL is a multi-disciplinary open access archive for the deposit and dissemination of scientific research documents, whether they are published or not. The documents may come from teaching and research institutions in France or abroad, or from public or private research centers.
L'archive ouverte pluridisciplinaire HAL, est destinée au dépôt et à la diffusion de documents scientifiques de niveau recherche, publiés ou non, émanant des établissements d'enseignement et de recherche français ou étrangers, des laboratoires publics ou privés. 


\title{
Hydromechanical interactions in a fractured carbonate reservoir inferred from hydraulic and mechanical measurements
}

\author{
F. Cappa (1) , Y. Guglielmi (1), P. Fénart (2), V. Merrien-Soukatchoff (3) and A. Thoraval (3) \\ (1) UMR 6526 Géosciences Azur, CNRS-UNSA, Tectonics and Geomechanics Division, 250 rue A. Einstein, \\ Sophia Antipolis, 06560 Valbonne, France \\ (2) Hydrofis, 3, avenue du Docteur Moriez, 06000 Nice, France \\ (3) INERIS-LAEGO, Ecole National Supérieure des Mines de Nancy, Parc de Saurupt, 54042 Nancy, France
}

\begin{abstract}
Hydromechanical coupled processes in a shallow fractured carbonate reservoir rock were investigated through field experiments coupled with analytical and numerical analyses. The experiments consist of hydraulic loading/unloading of a water reservoir in which fluid flow occurs mainly inside a heterogeneous fracture network made up of vertical faults and bedding planes. Hydromechanical response of the reservoir was measured using six pressure-normal displacement sensors located on discontinuities and two surface tiltmeters. A dual hydraulic behavior was characterized for low-permeability bedding planes well connected to highpermeability faults. Displacement responses show high-variability, nonlinear changes, sometimes with high-frequency oscillations, and a large scattering of magnitudes. Initial normal stiffnesses and effective normal stresses along fault planes were estimated in the field by interpreting pressure-normal displacement relations with a nonlinear function between effective normal stress and normal displacement. Two-dimensional discontinuum modeling with transient fluid flow was performed to fit measurements during hydraulic loading tests. Results show that the hydromechanical behavior of the reservoir is restored if a high stiffness contrast is allocated between low- and high-permeability discontinuities. Thus, a dualpermeability network of discontinuities will likely also be a contrasting stiffness network, in which the deformation of major flow-conducting discontinuities is significantly influenced by the stiffness of the surrounding less-permeable discontinuities.
\end{abstract}

Keywords: Hydromechanical coupling; Fractured rocks; Mechanical; Permeability; In situ measurements

\section{Introduction}

In fractured rock with a low-permeability porous matrix, the main hydromechanical processes occur in the fracture network system. Coupled hydromechanical processes in such fractured rock are particularly difficult to characterize, mainly because of the lack of knowledge related to the discontinuity network geometry, and the great variability of hydromechanical properties in both intact rock matrix and fractures. Many previous works have studied the hydromechanical behavior of fractured rock through laboratory experiments on a single deformable natural fracture [1], [2], [3], [4], [5], [6], [7], [8], [9], [10], [11] and [12], and some constitutive models including hydromechanical interactions have been proposed [4], [7], [13], [14], [15], [16], [17], [18] and [19]. However, because of scale effects, laboratory data can hardly be used for deriving the in situ hydromechanical properties of a fractured rock mass [20]. In situ field measurements appear to be essential determining the hydromechanical features of fractured rock [20], [21], [22], [23] and [24]. Commonly, these in situ measurements are based on hydraulic-well-testing methods [21] and [25] on single 
deformable discontinuities. Coupled with a back-calculation numerical analysis, these hydraulic tests can provide useful estimations of hydromechanical properties, but they do not allow a complete and accurate description of hydromechanical effects. To improve accuracy in estimating the hydromechanical properties of discontinuities, Rutqvist et al. [22] recommend combining hydraulic tests and mechanical displacement measurements. However, in situ tests on discontinuities that measure both hydraulic and mechanical responses are rare [3], [24], [26], [27], [28] and [29], and very few simultaneous in situ hydromechanical measurements of a discontinuous network have been carried out [29].

To improve our knowledge of hydromechanical couplings in shallow fractured reservoir rock, a medium-scale field experiment consisting of a hydraulic loading and unloading was performed in a water reservoir, to obtain values for some experimental parameters. Measured hydromechanical effects were analyzed through 2D coupled hydromechanical discontinuum modeling, using the distinct element code UDEC.

This paper first presents a detailed description of the experimental site. Second, results are presented of simultaneous hydraulic and mechanical measurements obtained during hydraulic well tests on single discontinuities, and from hydraulic loading and unloading of the rock mass. Then, a first attempt to analyze the experimental data was carried out, using an analytical solution based on the nonlinear Cundall and Hart joint model [15]. Thereafter, hydromechanical modeling is performed to fit experimental results, considering a relation between the changes in hydraulic aperture, normal stress, hydraulic pressure, and normal stiffness of the discontinuities. Finally, results are discussed both at the single discontinuity scale and at the entire reservoir scale.

\section{Experimental set up and hydrogeological context}

\subsection{Hydrogeological context}

The Coaraze Laboratory Site is located in the French Southern Alps (Fig. 1). This site corresponds to a natural reservoir $(30 \times 30 \mathrm{~m})$ made up of a $15 \mathrm{~m}$ thick pile of fractured limestone limited at the top and bottom by an impervious glauconious marl layer (Fig. 1). The fractured calcareous rock mass is drained by a spring (average annual yield of $121 \mathrm{~s}-1$ ) that appears directly on a vertical impervious fault contact between permeable limestone and impervious glauconious marls. This fault serves as a natural dam for the water stored in the reservoir. The spring is artificially closed with a water-gate; the piezometric level can be controlled in the reservoir by opening or closing the gate. Water from a fault, located $30 \mathrm{~m}$ upstream from the water-gate, continuously flows into the reservoir. The topographic surface was waterproofed with concrete to a $10 \mathrm{~m}$ height, to avoid water leakage from the discontinuities when water pressure increases. When the water-gate is closed, no more discharge occurs at the spring, and the pressure increases and stabilizes up to $10 \mathrm{~m}$ above the water-gate. When pressure stabilizes, two temporary springs (T1 and T2) overflow at the reservoir boundaries (Fig. 1). When the water-gate is opened, water stored in the reservoir flows out. The hydraulic boundaries of the reservoir are thus fully known and can be summarized as follows:

- Four impervious boundaries corresponding to the top and bottom geologic layers, the downstream fault zone, and the topographic surface covered with concrete 
- One permeable boundary corresponding to the upstream fault. During the experiments, small changes in pressure head along this fault (less than $5 \times 103 \mathrm{~Pa}$ ) suggest that the fault can be assumed to be a constant-pressure-head boundary.

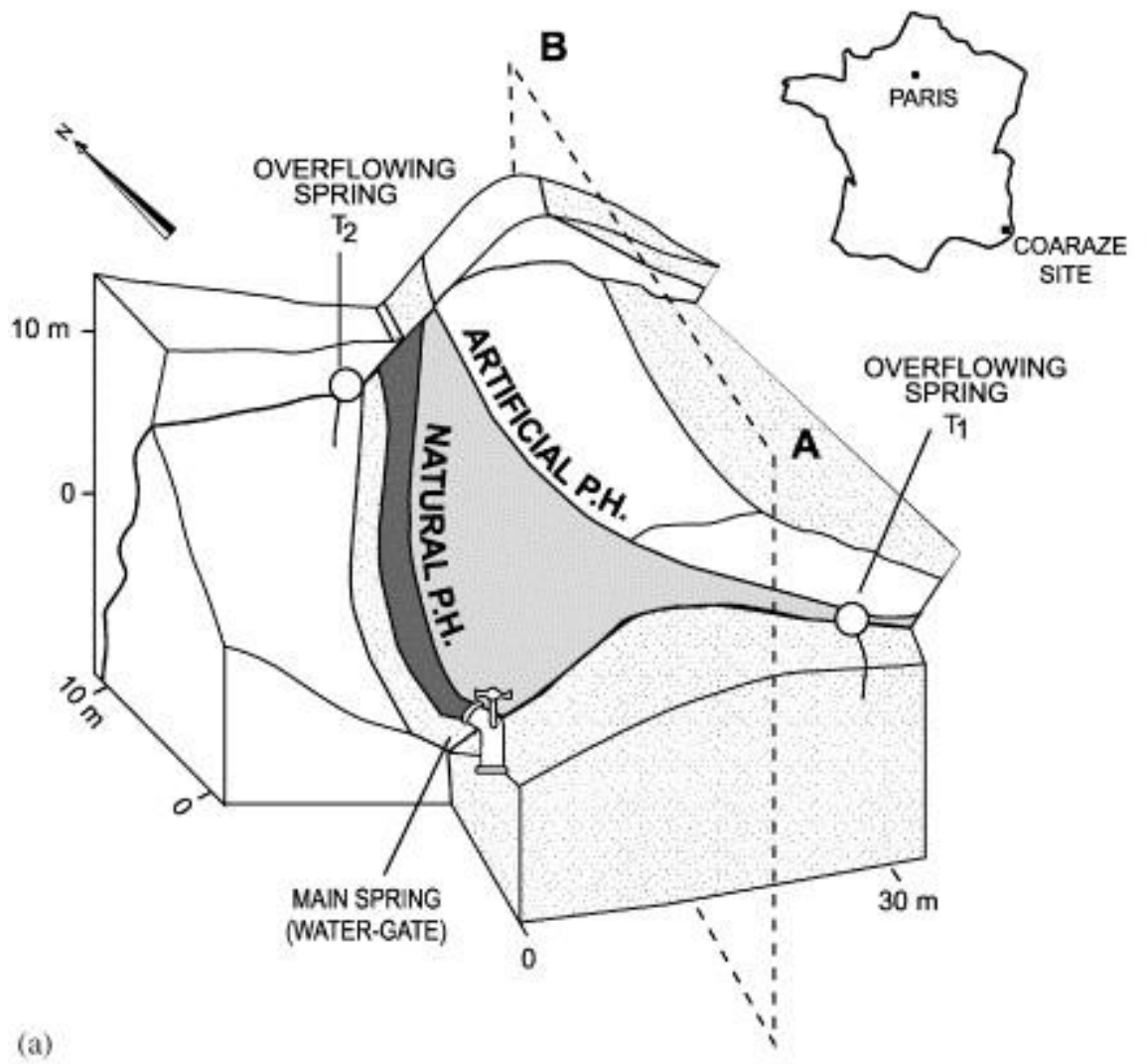

(a)
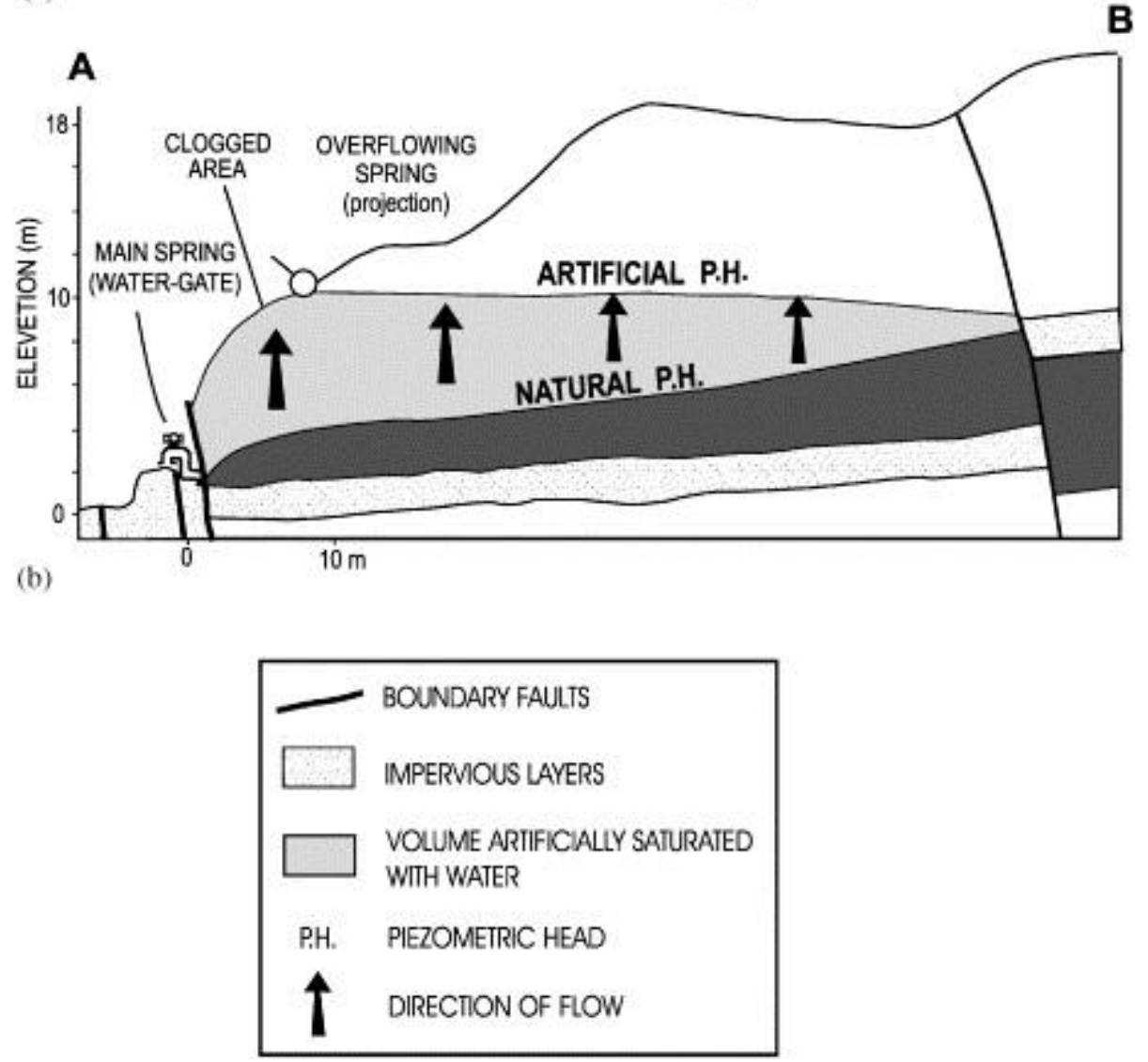
Fig. 1. Hydrogeological context (a) 3D view and (b) longitudinal cross section.

\subsection{Discontinuity network geometry}

Carbonate rocks at the Coaraze site present a regular stratification inherited from sedimentary processes, with two sets of orthogonal near-vertical brittle faults generated by a polyphased tectonic evolution during the Alpine orogeneses. From surface and boring scan-line data, the network can be characterized by 26 decametric discontinuities that extend over the boundaries of the reservoir and forming three sets (Figs. 2a, b and c):

- Three faults with a N50/N70 trend dipping $70^{\circ}-90^{\circ} \mathrm{NW}(\mathrm{F} 11, \mathrm{~F} 12$, and F13). These faults have a $2-3 \mathrm{~m}$ spacing.

- Eleven faults with a N120/N140 trend dipping $75^{\circ}-90^{\circ} \mathrm{NE}$ (F1 to F10 and F14) and with a 2 $\mathrm{m}$ spacing.

- Twelve bedding planes with a N40 trend dipping $45^{\circ} \mathrm{SE}$ (S1 to S12) and with a $0.5-1 \mathrm{~m}$ spacing. 

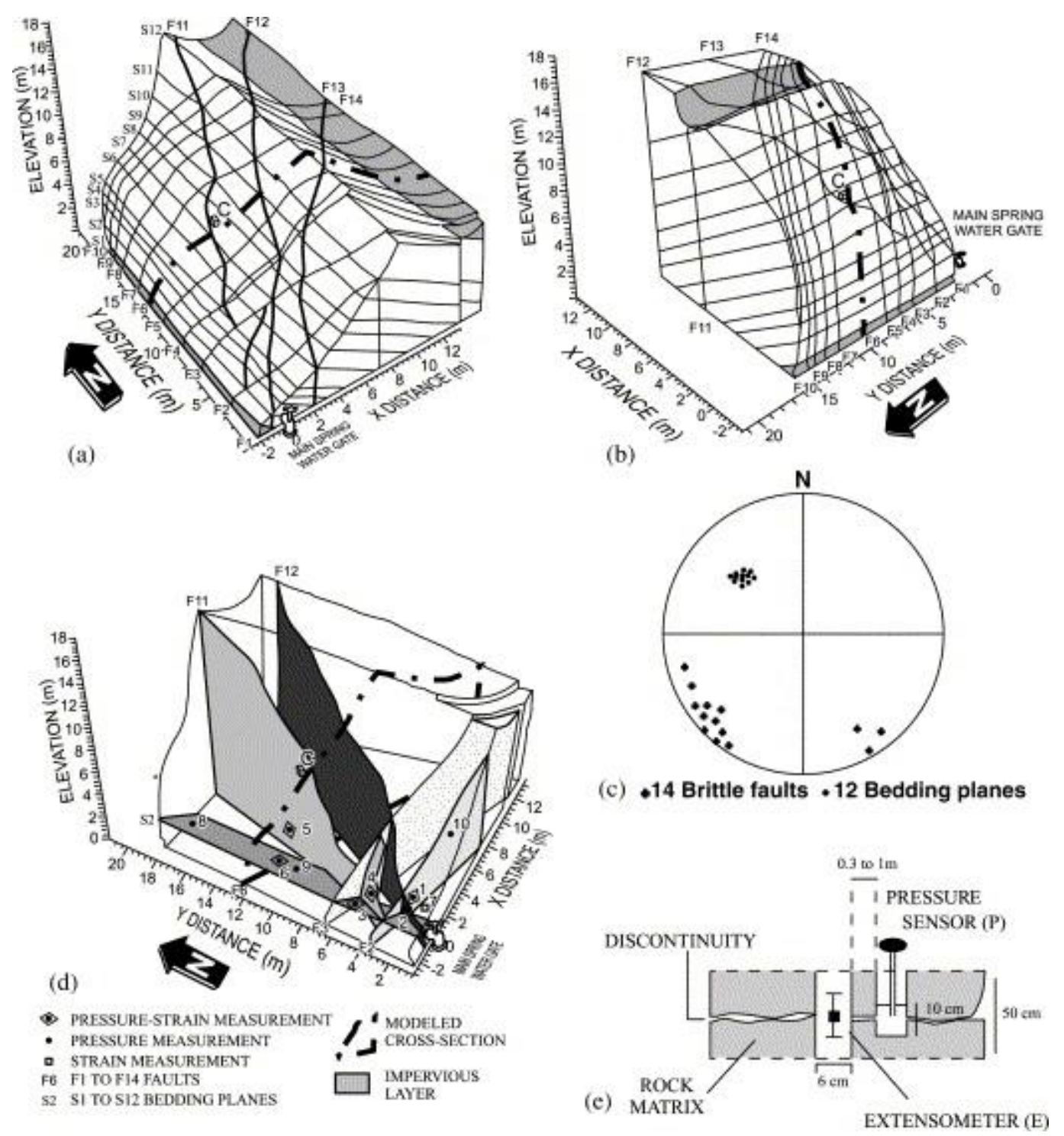

Fig. 2. (a,b) 3D geometrical model of rock mass fractures viewed from two angles. (c) Pole plots showing brittle faults and bedding planes orientations (lower hemisphere). (d) Experimental device. (e) Pressure-strain measurement device at the single joint scale.

Metric and below-metric discontinuities are sparse. Minor bedding planes appear parallel to the major bedding planes. Near-vertical faults correspond to a small brittle zone $(0.001-0.01$ $\mathrm{m}$ thick) with reverse kinematic.

At the single discontinuity scale, amplitude distribution of surface asperity was studied statistically on 61 profiles measured with CLA rating method, after Tse and Curden, and Fénart [32] and [33]. The surface roughness of major fault planes is larger than that of bedding planes with average values of asperity heights (CLA) being $1.4 \pm 0.3 \times 10-3$ and $0.5 \pm 0.2 \times 10-3 \mathrm{~m}$.

\subsection{Experimental set up}


Simultaneous in situ measurements of fluid pressures, rock matrix, and discontinuity strains are automatically and continuously monitored at various points to follow hydromechanical effects from the single discontinuity scale to the reservoir scale ([34] and Figs. 2b and d).

Six coupled pressure-strain measurements were located on the discontinuities that belong to the three discontinuity sets: point 1 inside the F2 fault; points 2, 4, and 5 inside the F11 and F12 faults; and, points 3 and 6 inside the S2 major bedding plane. In addition to these points, point 7 was sealed into the unfractured rock matrix and oriented parallel to bedding planes. At a so-called coupled pressure-strain point, two sensors were installed by two small borings (Fig. 2e) in order not to disturb the state of stress inside the reservoir. Pressure measurements were carried out using a vibrating-wire interstitial pressure sensors with an accuracy of $10 \mathrm{~Pa}$. Strain measurements are carried out with a $0.15 \mathrm{~m}$ long vibrating-wire extensometers, having an accuracy of $0.5 \mu \mathrm{m} / \mathrm{m}$.

At the topographic surface of the reservoir, two unidirectional tiltmeters are coupled to the rock near the F11 fault at a point located $10.9 \mathrm{~m}$ upstream and $10.2 \mathrm{~m}$ higher than the watergate, and 2-2.6 $\mathrm{m}$ above the maximum piezometric head in the unsaturated zone of the reservoir (Figs. 2a, b and d). At the measurement point, one tiltmeter measures tilt in a N150 trend and the other in a N60 trend. These are the two main vertical fault directions of the fracture network. These sensors are meant to better constrain the mechanical behavior at the boundary of the experimental zone.

\section{Hydraulical experiments}

\subsection{Testing procedure}

Tests were performed in three ways to characterize the hydraulic behavior of the rock mass at various scales:

1. Single fractures conductivities and storativities were characterized with slug tests.

2. Hydraulic connections between fractures and flow paths inside the fracture network were estimated with pump tests conducted at constant flow rate.

3. Storativity of discontinuities at the reservoir scale was estimated by water-gate closing experiments of different periods. Results of storativity were described in detail in Guglielmi and Mudry [35].

\subsection{High variability of discontinuity permeabilities from slug-test results}

Slug tests were measured at eight points (the six coupled pressure-strain measurement points and two others) where single discontinuities were isolated with inflatable packers. Slug tests were conducted with very low slug sizes in order not to induce mechanical deformation. Assuming (1) that the discontinuity apertures did not change with pressure and (2) that there was no exchange of water between the discontinuities and the rock matrix, the solution of Cooper et al. [36] was applied to analyze the tests.

There are two very different groups of values, corresponding to the bedding planes (points 6, 8, 9a, and 9b in Table 1 and Fig. 2) and the faults (points 1, 4, 5, and 10 in Table 1 and Fig. 
2). Fault hydraulic conductivities ranging from $0.57 \times 10^{-4}$ to $1.9 \times 10^{-4} \mathrm{~m} \mathrm{~s}-1$ appear to be two orders of magnitude higher than that of bedding planes $\left(0.9 \times 10^{-6}\right.$ and $\left.7.6 \times 10^{-6} \mathrm{~m} \mathrm{~s}^{-1}\right)$. Fault storativities, ranging from $0.7 \times 10^{-8}$ to $3 \times 10^{-8}$, are three orders of magnitude higher than that of bedding planes $\left(0.5 \times 10^{-11}\right.$ and $\left.3.4 \times 10^{-11}\right)$. Within the groups, there is a $10-30 \%$ variation, sometimes within the same discontinuity (e.g., points 1 and 10 on fault F3, points 4 and 5 on fault F11, and points 6 and 8 on bedding plane S2). This scattering can be taken as representative for hydraulic conductivity results, because it is larger than the classical uncertainty (20\%) introduced by Cooper's solution for the results [37] and [38].

Table 1. Hydraulic and mechanical properties of discontinuities and rock matrix

\begin{tabular}{|c|c|c|c|c|c|c|c|c|c|}
\hline \multirow{2}{*}{$\begin{array}{l}\text { Measuring } \\
\text { point }\end{array}$} & \multirow{2}{*}{$\begin{array}{c}\text { Type of } \\
\text { discontinuities }\end{array}$} & \multicolumn{4}{|c|}{ Hydraulic parameters } & \multicolumn{4}{|c|}{ Mechanical parameters } \\
\hline & & $\underset{\left(\mathbf{m} \cdot \mathbf{s}^{-1}\right.}{\mathbf{K}}$ & 1 ) & $\begin{array}{l}\text { Bh } \\
(\mathbf{m})\end{array}$ & $\begin{array}{l}\delta \mathbf{U} \\
(\mathbf{m})\end{array}$ & & a.m ${ }^{-1}$ & $\begin{array}{c}\mathbf{a}_{n} \\
\left(\mathbf{P a}^{-1} \cdot \mathbf{m}^{-1}\right)\end{array}$ & $\begin{array}{l}\sigma_{n 1}^{\prime} \\
(\mathbf{P a})\end{array}$ \\
\hline 1 & Fault F2 & $5.7 \times 10^{-5}$ & $0.7 \times 10^{-8}$ & $2.6 \times 10^{-4}$ & $1.3\rangle$ & $0^{-6}$ & 132 & 3.33 & $1.99 \times 10^{5}$ \\
\hline 2 & Fault F12 & $\mathrm{X}$ & $\mathrm{X}$ & $\mathrm{X}$ & $4.4 \times 1$ & $10^{-6}$ & 66 & 19.6 & $5.79 \times 10^{4}$ \\
\hline 3 & Bedding plane S2 & $X$ & $\mathrm{X}$ & $X$ & $9.6 \times$ & $10^{-8}$ & 20 & $X$ & $\mathrm{X}$ \\
\hline 4 & Fault F11 & $2.3 \times 10^{-4}$ & $2.6 \times 10^{-8} 5$ & $5.3 \times 10^{-4}$ & $1 \times 1$ & & 1.4 & 0.54 & $5.1 \times 10^{4}$ \\
\hline 5 & Fault F11 & $1.9 \times 10^{-4}$ & $1.9 \times 10^{-8}$ & $4.8 \times 10^{-4}$ & $1 \times 1$ & & 7.2 & 0.29 & $1.58 \times 10^{5}$ \\
\hline 6 & Bedding plane $\mathrm{S} 2$ & $7.6 \times 10^{-6}$ & $3.4 \times 10^{-11}$ & ${ }^{1} 9.6 \times 10^{-5}$ & $59.6 \times 1$ & $10^{-8}$ & 20 & $\mathrm{X}$ & $\mathrm{X}$ \\
\hline 8 & Bedding plane $S 2$ & $3.8 \times 10^{-6}$ & $2.1 \times 10^{-11}$ & ${ }^{1} 6.8 \times 10^{-5}$ & $-5 \quad X$ & & 20 & $X$ & $X$ \\
\hline $9 \mathrm{a}$ & Bedding plane $\mathrm{S} 2$ & $3.2 \times 10^{-6}$ & $1.8 \times 10^{-11}$ & $16.2 \times 10^{-5}$ & ${ }^{-5} \quad X$ & & 20 & $X$ & $X$ \\
\hline $9 b$ & Bedding plane $S 3$ & $9.0 \times 10^{-7}$ & $0.5 \times 10^{-11}$ & $113.3 \times 10^{-5}$ & ${ }^{-5} \quad X$ & & 20 & $X$ & $X$ \\
\hline 10 & Fault F2 & $2.0 \times 10^{-4}$ & $3 \times 10^{-8}$ & $4.9 \times 10^{-4}$ & $\mathrm{X}$ & & $\mathrm{X}$ & $X$ & $X$ \\
\hline 7 & Rock matrix & $\operatorname{Im} 1$ & pervious & & $E=70$ & $\mathrm{~Pa}$ & $v=0$. & $9 ; d=240$ & $00 \mathrm{~kg} \cdot \mathrm{m}^{-3}$ \\
\hline
\end{tabular}

(K: hydraulic conductivity; S: storativity; Bh: measured hydraulic aperture; dU: maximum normal displacement; kn1: initial normal stiffness; an: parameter of CYJM model; s'n1: initial normal stress; E: Young's modulus; ?:

Poisson's ratio; d: mass density).

From hydraulic conductivity values, the hydraulic apertures $(\mathrm{Bh})$ of discontinuities were estimated using the classical relation established by Witherspoon et al. [31] assuming that the flow inside the discontinuity follows the cubic law. Fault apertures range between $2.6 \times 10-4$ and $5.4 \times 10-4 \mathrm{~m}(4.4 \times 10-4 \mathrm{~m}$ mean value $)$ and bedding plane values range between $3.3 \times 10-5$ and $9.6 \times 10-5 \mathrm{~m}(6.5 \times 10-5 \mathrm{~m}$ mean value $)$.

\subsection{Connectivity of the discontinuity network}

To detect connections between the discontinuities, constant-rate pumping tests were carried out at the eight different points. A pumping test was performed at one point while drawdown was synchronously followed at all the other points. We present the pump test (rate: $1.43 \times 10-3$ $1 \mathrm{~s}-1$ during $34 \mathrm{mn}$ ) performed at point 4 on fault F11 (Fig. 2 and Fig. 3). 


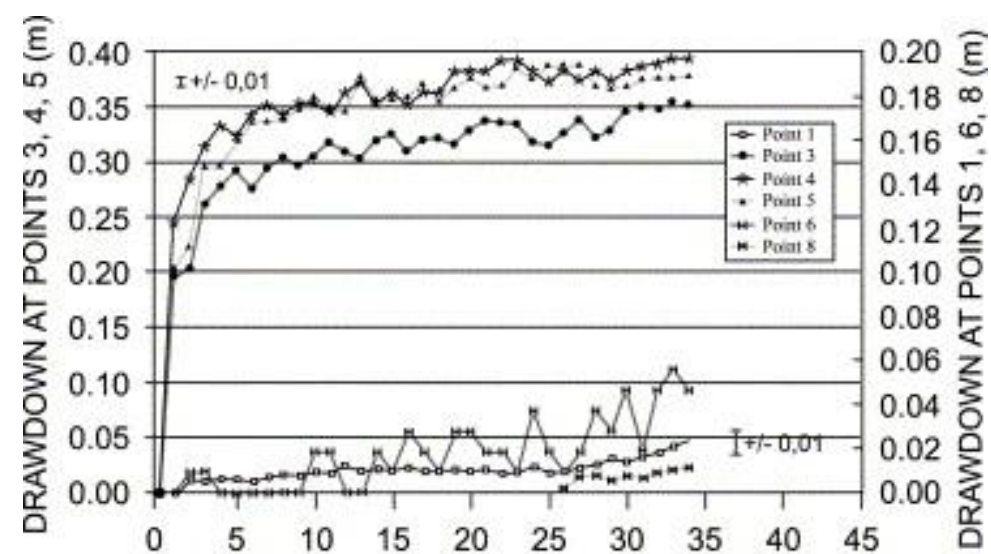

(a)

TIME SINCE PUMPING STARTED $(\mathrm{mn})$
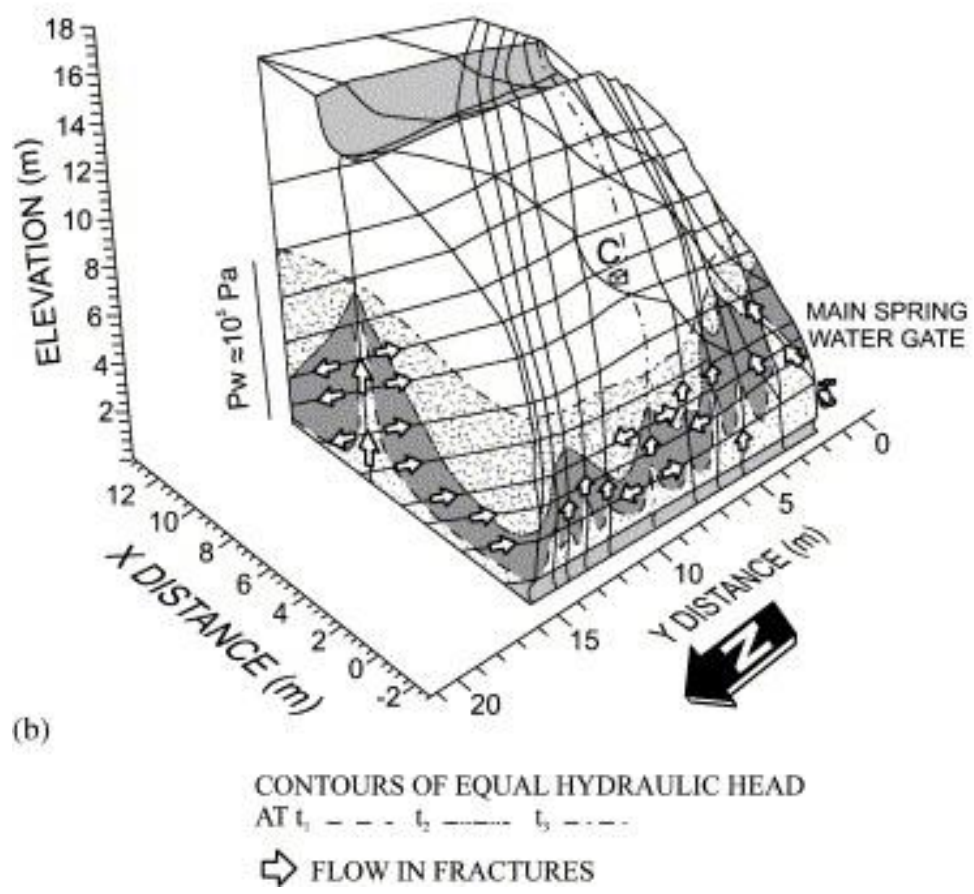

Fig. 3. (a) Results of pump tests. (b) Conceptual flow model.

The drawdowns in the faults (points 1,4 and 5) all show two characteristic periods: a steep nonlinear early slope $(0-10 \mathrm{mn})$, followed by a low inclination linear slope for the rest of the test (11-34 mn). In the bedding planes, the drawdown at point 6 shows significant oscillations, characterizing the response of the bedding plane to the pressure fall in fault F11. For this reason, the fault can be taken as a constant pressure boundary for the bedding plane. The drawdown curves typically represent the hydraulic behavior of a dual-permeability aquifer, in which pressure drops first in the highly permeable faults and then in the less permeable bedding planes [39].

Taking into account the magnitude of the response in the highly permeable faults, point 5 is very well connected to point 4 , because the drawdown at the two points are similar (also, other pumping tests performed at point 5 showed similar to that performed at point 4). This fact suggests that a high permeability zone links the two points within the fault F11 plane. 
Points 1 and 3, while close to the pumped point, show smaller responses. For this reason, they can be taken as medium (point 3 ) to poorly (point 1) connected to point 4 . This means that a low to medium permeability zone links faults F11 and F2, and the fault F11, with the bedding plane S2. As a consequence, flow in the faults appears strongly inhomogeneous and noncylindrical at the metric scale.

\subsection{Conceptual model}

The hydraulic behavior of the site can be characterized as follows:

- The existence of a dual permeability discontinuity network with highly permeable faults and low permeability bedding planes.

- $10-30 \%$ scattering of hydraulic conductivity within the single discontinuity planes.

- High connectivity of the discontinuities.

Previous hydraulic quantifications [35] showed that the storativity of major faults only represents $4 \%$ of aquifer storativity. The remaining $96 \%$ corresponds to storage in the bedding planes, with an apparently major role played by minor metric bedding planes.

These results suggest two major hydraulic behaviors within the discontinuity network (Fig. $3 b)$. First, the high hydraulic-conductivity contrast between the discontinuities $(\mathrm{Kf} / \mathrm{Kbp}=100)$ denotes that the reservoir is drained by the fault network, with, faults representing hydraulic boundaries for connected bedding planes. Second, large-scale storage experiments [35] have emphasized the role played by metric bedding planes, which could be taken as an effect of the anisotropic porous matrix.

\section{Hydromechanical experiments}

The loading experiment analyzed in this paper began when the water-gate was completely closed ( $\mathrm{t}=0$ on the graphs in Fig. 4). There is a rapid pressure build-up in the faults to steady state (points 1, 2, 4, 5) and in zones of bedding planes very close to faults (point 3). In zones of bedding planes that are distant from faults (point 6), the pressure rise is slower. Since all measuring points are roughly set at the same elevation, pressure heads above the points are about the same, ranging from 50 to $55 \mathrm{kPa}$. The experiment duration was set to 23 min (grey zone on graphs of Fig. 4). After $23 \mathrm{~min}$, the water-gate is re-opened. Pressure falls in $1 \mathrm{~min}$ within the faults and in the bedding plane zones close to faults (point 3), whereas it keeps on rising in the bedding plane zones further away from the faults (point 6). 

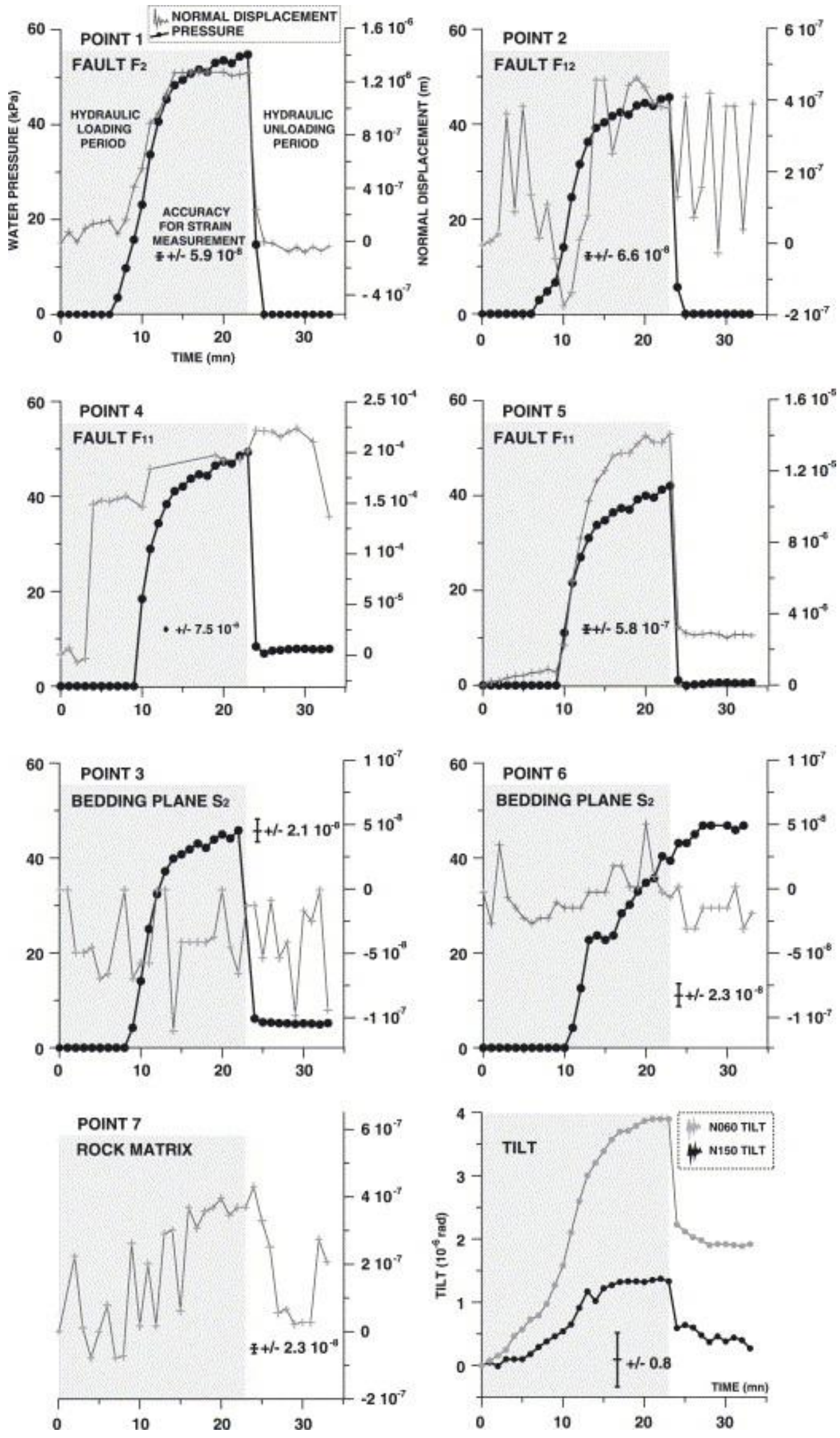

Fig. 4. Comparison of hydromechanical responses in faults, bedding planes, and rock matrix caused by a 23 min long hydraulic loading. 


\subsection{Analysis of synchronous temporal signals of in situ pressure and normal displacements}

When the water-gate is closed, normal displacement measurements display highly variable nonlinear signals, whose response and amplitude more or less correlate with pressure variations at points (Fig. 4). A hysteresis of variable amplitude (large to moderate at points 1 , 4, and 5, and null at points 2, 6 and 7) appears between increasing and decreasing pressure changes. For sufficiently long waiting times at the end of experiments, normal displacement measurements generally return to initial values. Thus, the mechanical behavior of the rock mass appears to be elastic for the low-hydrostatic-pressure experiments carried out on the site. The slow return of the normal displacement to its initial state, at points located on the faults, is interpreted as being associated to water stored into zones close to the fault that flows towards the fault. The zones close to the fault may correspond to the connected bedding planes.

\subsubsection{High variability of normal displacements responses}

Points 1 and 5 are the only points where normal displacement response is qualitatively identical to pressure response. An early dynamic opening occurs when pressure starts elevating above the points until pressure has reached about $90 \%$ of its final value. Then, a linear opening follows until the end of the experiment. The closure is as quick as the pressure drop. All the other points show generally noisy normal displacement responses, often altered, compared to pressure variations at the points. At point 3, the very noisy normal displacement response displays no obvious correlation with pressure loading. At points 2, 4, and 6, normal displacement responses look similar. In the early stage (between 0 and $10 \mathrm{~min}$ ), curves display oscillations without any pressure rise above the point. This means that during this time period, local normal displacement responses result from total stress variations inside the fracture network. The oscillations correspond to opening and closing of the discontinuity, over an average period of $3 \mathrm{~min}$ (unfortunately, the sampling frequency employed $(0.02 \mathrm{~Hz})$ appears insufficient to give a good restoration of the signal). After $10 \mathrm{mn}$, the discontinuity opens, following a pressure rise above the point that is still highly nonlinear. When pressure falls, the responses appear very noisy at all points, and there is a clear time lag between the mechanical normal displacement and the pressure fall. Oscillations roughly similar to the early ones were observed. For long-enough waiting times at the end of experiments, a damping of normal displacement responses occurs, along with a return to initial low-noise values.

There is a clear difference between the high magnitude values for normal fault displacements at points $1,2,4$ and $5(1.3 \times 10-6,4.7 \times 10-7,2.25 \times 10-4$ and $1.4 \times 10-5 \mathrm{~m}$, respectively) and, the very low to null amplitude values of bedding planes points 3 and $6(1.05 \times 10-7$ and $5 \times 10-8 \mathrm{~m}$, respectively). Such a scatter will be examined further, since it can result from a different state of stress at the measuring point (bedding planes being more pressurized than faults) or from different geometrical characteristics of the discontinuities (faults surface roughnesses being very different from bedding plane roughnesses).

\subsubsection{Rock matrix deformation}

Point 7 measures the response during pressure build up within the discontinuity network. Highly dynamic responses occurred at points 2 or 6 , suggesting that it can be linked to the normal displacement response of these discontinuities. Magnitudes that range from $-0.7 \times 10-7$ 
to $4.5 \times 10-7 \mathrm{~m}$ display intermediate values between those of the bedding planes and those of the faults.

\subsubsection{Synthesis}

Points 1 and 5 display typical coupled responses as can be found in other in situ experiments [3], [24], [26] and [29]. In all those experiments, such a response was obtained from the injection of water in a pressurized single fracture. In fluid injections, this assumption is often made according to which the total stress of the rock mass was unchanged [40]. Thus, the distribution of fluid pressure within the fracture plane determines the changes in effective normal stress acting across the fracture-hence the magnitude of the change in aperture.

In the Coaraze experiments, the pressure loading procedure is very different, because water injection is generalized at the discontinuity network scale. Thus, total stress in the rock mass changed when pressure was increased. This means that normal displacement responses at one point result from pressure rises above the point within the discontinuity, and from total stress/strain variations around the discontinuity. At points 1 and 5, it seems that the normal displacement response is clearly linked to the hydraulic pressure rise. This can be explained by the high discontinuity permeability at these points. Nevertheless, the linear part of the responses after $10 \mathrm{~min}$ time certainly also results from normal displacement variations at the network scale, caused by the high connectivity between discontinuities. The influence of total stress/strain changes is clearly demonstrated by the responses of the other point which display strain oscillations independent from pressures changes above the points.

\subsection{Boundary effects from tilt measurements}

Tilt curves are nonlinear, similar to the one of the normal displacement of fault versus time measured at point 5 (Fig. 4). When the water-gate is closed, the tilt signals are characterized by a N150 tilt ranging from 0 to $1.3 \times 10-6$ rad, and N60 tilt ranging from 0 to $3.95 \times 10-6$ rad. In more detail, during water-pressure elevation $(23 \mathrm{~min})$, positive tilt variations correspond to an overall rotation of the rock mass towards the interior of the slope. Between 13 and 15 min, the tilt curves show second-order reverse peak, mainly on the N150 trend that is not visible on the fault displacement curve. This peak corresponds to a displacement towards the exterior of the rock mass (negative tilt variation) followed by a displacement towards the interior. This is clearly not correlated with any displacement response at different points. When the water-gate is opened, a rapid variation of surface tilt occurs in $1 \mathrm{~min}$, followed by a residual rotation with a slow return (time lag of $9 \mathrm{mn}$ for N150 tilt) to the initial state (Fig. 4). Pressure fall induces a negative tilt variation which corresponds to a quick movement towards the exterior of the rock mass.

This experiment clearly shows that surface tilts display smooth responses that, as a first approximation, look like the F11 fault displacement curve. This fact denotes that boundary effects (at the topographic surface) seem to result from hydromechanical responses at the depth of the most permeable discontinuities of the reservoir (as has already been observed in other case studies [41], [42], [43], [44] and [45]). One interpretation would be to consider that the discontinuities have a low stiffness value or are subject to lower stresses compared to other discontinuities. Thus, a coupled effect occurs in which high permeability and weak mechanical properties reinforce each other to amplify deformation at the free surface of the reservoir. 


\subsection{Analysis of pressure-normal displacements curves}

\subsubsection{Objectives and analysis procedure}

The objective is to obtain in situ mechanical properties of discontinuities from the analysis of pressure/normal displacement curves that can be used as input parameters for numerical modeling purposes (developed in Section 5). We focus on the periods where normal displacement response follows pressure rise above the measuring point. As has been shown in Section 4.1.1, such responses are less noisy within the faults than within bedding planes. For this reason, only the mechanical properties of faults have been estimated at points 1, 2, 4, and 5 (Fig. 5). Bedding planes stiffnesses were determined from literature data (Table 1).
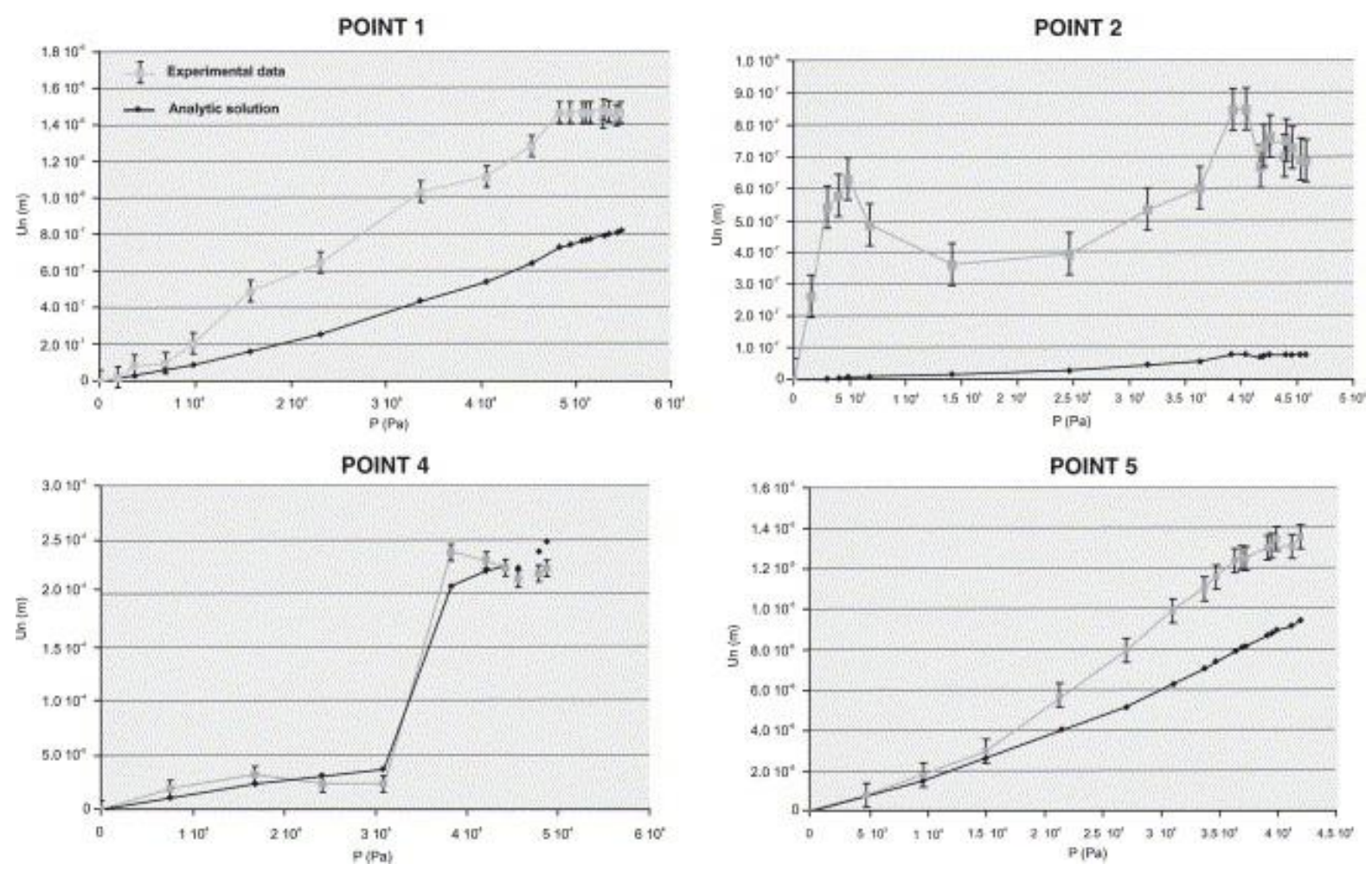

Fig. 5. Comparison of the Un/P relationship inferred from the in situ measurements and the back-calculation with modified Cundall and Hart's formulation.

Measured curves of normal displacement as a function of pressure (Fig. 5) present a hyperbolic form typical of a nonlinear function, linking effective normal stress to normal displacement (as has been described in numerous laboratory tests [7], [13] and [15]). Pressure/normal displacement curves are analyzed using an analytical approach, derived from the Cundall and Hart formulation [15] given in the following section. In this formulation, tangential displacement is neglected because no measurements of shear stress have been performed during experiments.

\subsubsection{Analytical formulation}

Cundall and Hart [15] proposed a hyperbolic function to fit the effective normal stress-normal displacement relation, and to express the normal joint stiffness kn as follows: 


$$
k_{n}=\frac{\partial \sigma_{n t}^{s}}{\partial U_{n}}=a_{n} \sigma_{n}^{\ell_{n}}
$$

where is the effective normal stress, Un is the closure of the discontinuity, and, an and en are model parameters (en is usually taken equal to 2 ).

The relation between the stress and closure will be completely defined, knowing the value of the discontinuity closure Un1 for a given normal stress .

Thus, the normal displacement change ?Un(1-2)(=Un2-Un1) due to variation in effective normal stress from to can be expressed by the following linear relationship between

$$
\frac{\Delta U_{n(1-2)}}{\Delta \sigma_{n(1-2)}^{\prime}}=\frac{1}{a_{n} \sigma_{n \mathbb{1}}^{n \varphi_{n}}}+\frac{\Delta U_{n(1-2)}}{\sigma_{n \mathbb{1}}^{s}}
$$

The raw data are the pressures versus normal displacements. Pressure can be introduced in Eq. (2) using a simplified formulation of the effective normal stress. In fact, Duveau et al. [19] defined the effective normal stress inferred from hydromechanical laboratory tests on a single discontinuity under normal loading [46] and [47] as follows:

$$
\sigma_{n}^{\prime}=\sigma_{n}-P\left(1-S_{\mathbb{C}}\right)
$$

In this formulation, $\mathrm{P}$ is the pressure within the two planes of the discontinuity, and $\mathrm{Sc}$ is the constant area ratio. This model enables the description of discontinuity behavior under a pressure rise that remains inferior to total normal stress sn, which is the case of the Coaraze experiments. A parameter $(1-\mathrm{Sc})$ is defined to take into account the nonuniform pressure distribution within the discontinuity, which can be described as a succession of co-planar voids separated by contact zones with a constant area ratio $\mathrm{Sc}(0<\mathrm{Sc}<1)$.

From experimental results, the effective normal stress change according to a pressure change can be expressed as follows:

$$
\Delta \sigma_{n(1-2)}^{\prime \prime}=\Delta \sigma_{n(1-2)}-\Delta P_{(\mathbb{1}-2)}\left(1-S_{\mathbb{Q}}\right)_{s}
$$

By introducing Eq. (4) in Eq. (2), it appears that too many unknown parameters exist. Therefore, this equation doesn't lead to a unique solution. For this reason, and in order to have a rough analytical estimation of the stiffness, we consider the particular case in which ? $\operatorname{sn}(1-$ 2 ) $=0$. A linear relationship is then expressed between :

$$
\begin{aligned}
\frac{\Delta U_{n(\mathbb{1}-2)}}{\Delta P_{(\mathbb{1}-2)}} & =-\frac{1-S_{\mathscr{C}}}{a_{n} \sigma_{n}^{\prime 2}}-\left(\frac{1-S_{\mathfrak{C}}}{\sigma_{n \mathbb{1}}^{\prime}}\right) \Delta U_{n(\mathbb{1}-2)} \\
& =A+B \Delta U_{n(1-2)}
\end{aligned}
$$


where is the effective normal stress at zero hydraulic pressure, and where

$$
A=\frac{-\left(1-S_{\mathbb{C}}\right)}{a_{n} \sigma_{\mathrm{m}}^{2}}
$$

and

$$
B=\frac{-\left(1-S_{\mathfrak{C}}\right)}{\sigma_{w l}^{\prime}}
$$

In Eq. (5), is the initial effective normal stress on the discontinuity before any pressure rise in the rock mass. The was estimated using a $2 \mathrm{D}$ numerical model of the reservoir simulating discontinuities not saturated with water. The reservoir is consolidated to compute the initial state of stress. The state of stress was assumed to result mainly from the weight of the geological unit and a stress field strongly influenced by the topographic surface. Estimated values of vary between 51 and $199 \mathrm{kPa}$, depending on the measuring points (Table 1). From these values, Sc was computed to fit measured pressure/normal displacement curves. Then, A and $\mathrm{B}$ were determined from the equation of the analytical line that best fits the experimental values.

Finally, an initial normal stiffness was recalculated as follows:

$$
k_{w 1}=\frac{-\left(1-S_{\complement}\right)}{A}=a_{n} \sigma_{w 1}^{2}
$$

$\mathrm{k}_{\mathrm{n} 1}$ is the normal stiffness, and the normal stress.

\subsubsection{Parameters identification}

Fig. 5 displays results from the analytical estimation of normal displacement versus pressure curves compared to experimental results. It clearly appears that the best fit is obtained for points 4 and 5, while the fit is very poor for points 1 and 2. Nevertheless, the mechanical properties of faults deduced from the analytical formulation must be taken with caution. A reasonable range of values was used for input parameters in the modeling performed in Section 5. Thus, the range for the initial normal stiffness $\mathrm{kn} 1$ of the faults scatters between 1.4 and $7.2 \mathrm{GPa} / \mathrm{m}$ for N60 faults, and between 66 and $132 \mathrm{GPa} / \mathrm{m}$ for N130 faults (Table 1). The stiffness of bedding planes was taken to be equal to $20 \mathrm{GPa} / \mathrm{m} \mathrm{[16]}$.

All the calculated curves (Fig. 5) were obtained for an Sc value ranging from 0 (Point 1 and 2 in Fig. 5) to 0.1 and 0.2 , respectively for points 4 and 5. This is certainly underestimated, because it means that surfaces in contact within the two planes of the discontinuity only correspond to $0-20 \%$ of the total discontinuity surface. Nevertheless, the mechanical behavior is estimated, it can be seen that there is a high discrepancy between the results of calculations and experiments at some points. This is interpreted as a strong effect of normal stress change on faults displacements, and that it was strongly abusive to fix this parameter to 0 in the analytical formulation. Looking in detail at the curves, one can observe that the discrepancy between calculated and experimental curves increases with pressure rise within the discontinuities (especially at points 1, 2, and 5 in Fig. 5). At the early portion of pressure rise 
in the fault, which corresponds roughly to the 3-5 values, water flows mainly within the two planes of the faults, and the hydromechanical effect is predominant close to the discontinuity. Later, deformation diffuses further into the surrounding rock mass, so that the variations in normal stresses become more influential.

\section{Analysis of hydromechanical effects at the scale of the fractured rock mass}

\subsection{Model geometry and input parameters}

A 2D hydromechanical numerical analysis was developed considering a $12 \times 16 \mathrm{~m}$ cross section perpendicular to the topographic surface (Fig. 6 and Figs. 2a and b). The discontinuities included in the model correspond to three N60 faults and eleven bedding planes (Figs. 2a, and b). This model was selected after studying the influence of boundary effects using a model with an extended width of $400 \mathrm{~m}$. The model is constrained by displacement-type boundary conditions (Fig. 6). The grid point is made up of triangular mesh elements whose sides are $0.25 \mathrm{~m}$ long. Mechanical features of the rock matrix were determined from laboratory tests (Table 1). Geological units included in the model have the same mechanical properties. Mechanical parameters of the discontinuities were previously determined (see Section 4.3.3, above). Shear stiffness was derived from kn using the relation $\mathrm{ks}=\mathrm{kn} / 10$ that can be used for shallow fractured rocks [48]. Hydraulic properties assigned to the discontinuity network are the initial hydraulic apertures (Bhi) at zero stress. Bhi is obtained from aperture values $(\mathrm{Bh})$ inferred from slug tests that were corrected with maximal normal displacement magnitudes (dU) measured at the different points (Bhi=Bh-dU) (Fig. 6). Hydraulic boundary conditions of the cross section are taken as impermeable. A quasi-static coupled hydromechanical calculation with transient fluid flow was performed, the fluid set to be compressible. 


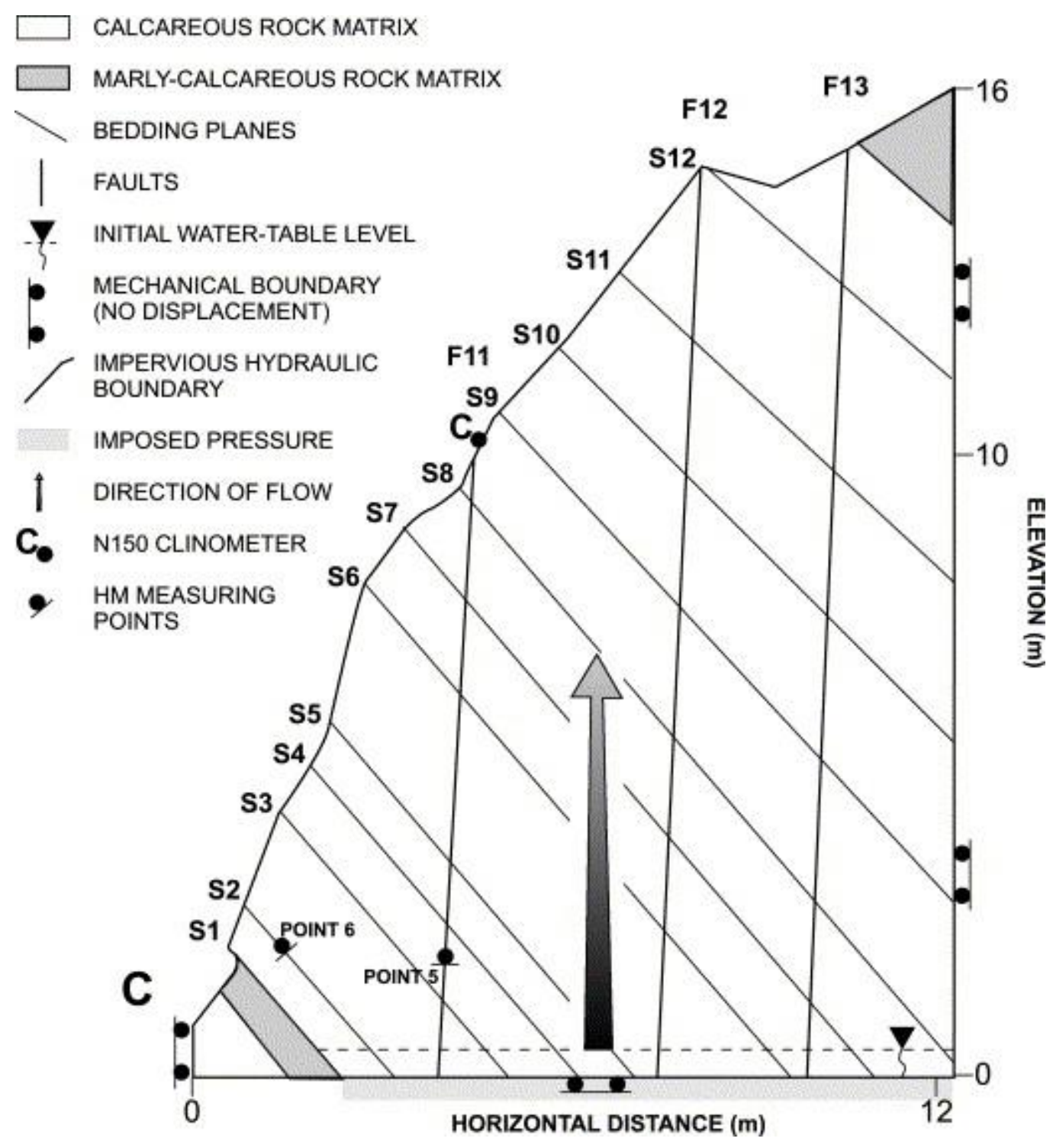

Fig. 6. Initial conditions of coupled hydromechanical modeling.

The coupled hydromechanical modeling was carried out in four successive stages. A rectangular geometry was first consolidated under gravity to compute the initial state of stress. Then, the stress modification induced by the excavation of the valley was computed. Vertical stresses were identical for each tests ranging from 0 to $3.2 \times 105 \mathrm{~Pa}$. The initial hydromechanical state was then computed considering that when the water-gate is opened, the water table level is $0.5 \mathrm{~m}$ higher than the water-gate (this is simulated applying a hydraulic pressure of $5 \mathrm{kPa}$ at the bottom of the model). The fourth stage corresponds strictly speaking to the "test". Hydraulic overloading () was applied with boundary conditions in pressure imposed at the base of the cross section. Then, hydromechanical effects were monitored with pressure and displacement fields at three control points $(5,6$, and $C)$ inside and on the surface of the cross section.

\subsection{Numerical modeling at the rock mass scale}

Two-dimensional numerical calculations were performed with the UDEC code [50] which uses the distinct element method [49] to model the coupled effects of stress-flow. Two 
dimensional modeling was justified by the evidence that a direct application of 3D discontinuity data can result in an extremely complex model, one that is unmanageable in terms of solution run times. A balance was made to reproduce the important geological elements and their effects on the modeled mechanisms with an efficient 2D model. The simulated rock mass was assumed to consist of an assemblage of blocks interfaced by discrete discontinuities [50]. In UDEC, the deformation of fractured rock consists in the elastic and/or plastic deformation of intact rock blocks, and of displacements along and across discontinuities [51]. For purely elastic behavior, the concept of "deformable fracture", caused by a nonlinear relation between effective normal stress and normal displacement, was introduced in UDEC through the Continuously Yielding Joint Model "CYJM" (see Eq. (1)) proposed by Cundall and Hart [15] and later revised by Lemos [17].

A fully coupled hydromechanical analysis was performed in which hydraulic conductivity is dependent on the mechanical displacement of discontinuities and on matrix deformation; conversely, fluid pressures affect the mechanical behavior [52]. The blocks are impermeable and bounded by fluid-filled discrete discontinuities. Fluid flow is calculated using the classical cubic law based on the parallel plate model [30] and [31]. The hydraulic aperture " $\mathrm{B}_{\mathrm{h}}$ " of the discontinuity at a given normal stress is updated according to its mechanical normal displacement variation " $\Delta \mathrm{U}_{\mathrm{n}}$ ", following the relation:

$$
\mathrm{B}_{\mathrm{h}}=\mathrm{B}_{\mathrm{hi}}+\Delta \mathrm{U}_{\mathrm{n}}
$$

where $\mathrm{B}_{\mathrm{h}} \mathrm{i}$ is the initial hydraulic aperture at the initial reference effective normal stress, .

\subsection{Parametric study}

\subsubsection{Modeling procedure}

The modeling aims at estimating the reservoir's hydromechanical behavior, given a set of measurements that correspond to one surface tilt and two deep coupled pressure/normal displacements, respectively, located on a fault (point 5 in fault F11) and on a bedding plane (point 6 on bedding plane S2).

Because the input parameters exhibit wide variability within one discontinuity type and between the two main types of discontinuities, measurement values at point 5 and 6 are neither necessarily representative of the hydromechanical behavior of all discontinuity plane zones, nor representative of the hydromechanical response for the other discontinuities of the same type. To solve this scale and heterogeneity-effect problem, a reference case (test 1) was defined with the input parameters presented in Table 2 . Then, test 1 was used as a reference in a sensitivity study to address the importance of each of the input parameters on the hydromechanical behavior of the discontinuities network (Table 2). 
Table 2. Hydromechanical properties used in the 11 parametric tests

\begin{tabular}{|c|c|c|c|c|c|c|}
\hline \multirow[t]{2}{*}{ Test } & \multicolumn{3}{|c|}{$\begin{array}{l}\text { Initial normal stiffness " } k_{n 1} \text { " } \\
(\mathbf{G P a} / \mathbf{m})\end{array}$} & \multicolumn{2}{|c|}{$\begin{array}{l}\text { Initial hydraulic aperture } \\
\text { "Bhi" (m) }\left(B_{h i}=B_{h}-\delta U\right)\end{array}$} & \multirow[t]{2}{*}{$\begin{array}{l}\text { Young modulus } \\
\text { "E" (GPa) }\end{array}$} \\
\hline & $\begin{array}{l}\text { Fault } \\
\mathbf{k}_{\mathrm{n} 1}\end{array}$ & & Bedding plane & Fault B & ng plane & \\
\hline 1 & 7.2 & 0.29 & 20 & $3.9 \times 10^{-4}$ & $8.2 \times 10^{-5}$ & \\
\hline 2 & 7.2 & 0.29 & 20 & $4.3 \times 10^{-4}$ & $9.6 \times 10^{-5}$ & \\
\hline 3 & 7.2 & 0.29 & 20 & $2.6 \times 10^{-4}$ & $6.8 \times 10^{-5}$ & \\
\hline 4 & 7.2 & 0.29 & 20 & $4.3 \times 10^{-4}$ & $6.8 \times 10^{-5}$ & \\
\hline 5 & 7.2 & 0.29 & 50 & $3.9 \times 10^{-4}$ & $8.2 \times 10^{-5}$ & \\
\hline 6 & 7.2 & 0.29 & 100 & $3.9 \times 10^{-4}$ & $8.2 \times 10^{-5}$ & \\
\hline 7 & 7.2 & 0.29 & 500 & $3.9 \times 10^{-4}$ & $8.2 \times 10^{-5}$ & \\
\hline 8 & 132 & 3.33 & 20 & $3.9 \times 10^{-4}$ & $8.2 \times 10^{-5}$ & \\
\hline 9 & 70 & 1.81 & 20 & $3.9 \times 10^{-4}$ & $8.2 \times 10^{-5}$ & 70 \\
\hline 10 & 7.2 & 0.29 & 20 & $3.9 \times 10^{-4}$ & $8.2 \times 10^{-5}$ & 90 \\
\hline 11 & 7.2 & 0.29 & 20 & $3.9 \times 10^{-4}$ & $8.2 \times 10^{-5}$ & 50 \\
\hline
\end{tabular}

In this parametric modeling, the CYJM nonlinear model was assumed for faults. A constant stiffness was applied for bedding planes because the normal stress does not vary much; as a matter of fact, the magnitudes of normal displacements are very small ( 0 at point 3 , and $5 \times 10$ $8 \mathrm{~m}$ at point 6). Rock matrix behavior is taken as linearly elastic and isotropic.

\subsubsection{Description of test 1 reference case}

We review the test 1 reference case results with special attention to pressure/normal displacement variations (Figs. 7a and c), time variations (Figs. 7b and d) and surface tilt variations (Fig. 7e). The calculated water pressure-normal displacement relation at point 5 on fault F11 best fits the experimental data (Fig. 7a). Considering a low effective normal stress and a low fault plane stiffness, and taking into account the influence of the surrounding bedding planes, the pressure-displacement relation is well approximated with a nonlinear discontinuity behavior. This implies that the hydromechanical behavior of the fault is intimately dependent on fault stiffness, initial normal stress, and ambient joint features. The modeling shows that the fault opens continuously as the pressure rises. The bedding plane S2 (point 6) closes for a null pressure ( $-4 \times 10-7 \mathrm{~m}$ closure in Fig. $7 \mathrm{c})$, and then opens with pressure rise. Values of normal displacement in the bedding plane were overestimated by a factor of 15, and the shapes of calculated curves for normal displacement are far from the measured ones (Fig. 7c) because of the low stiffness allocated to bedding planes to best fit the hydromechanical measurements of fault F11. 

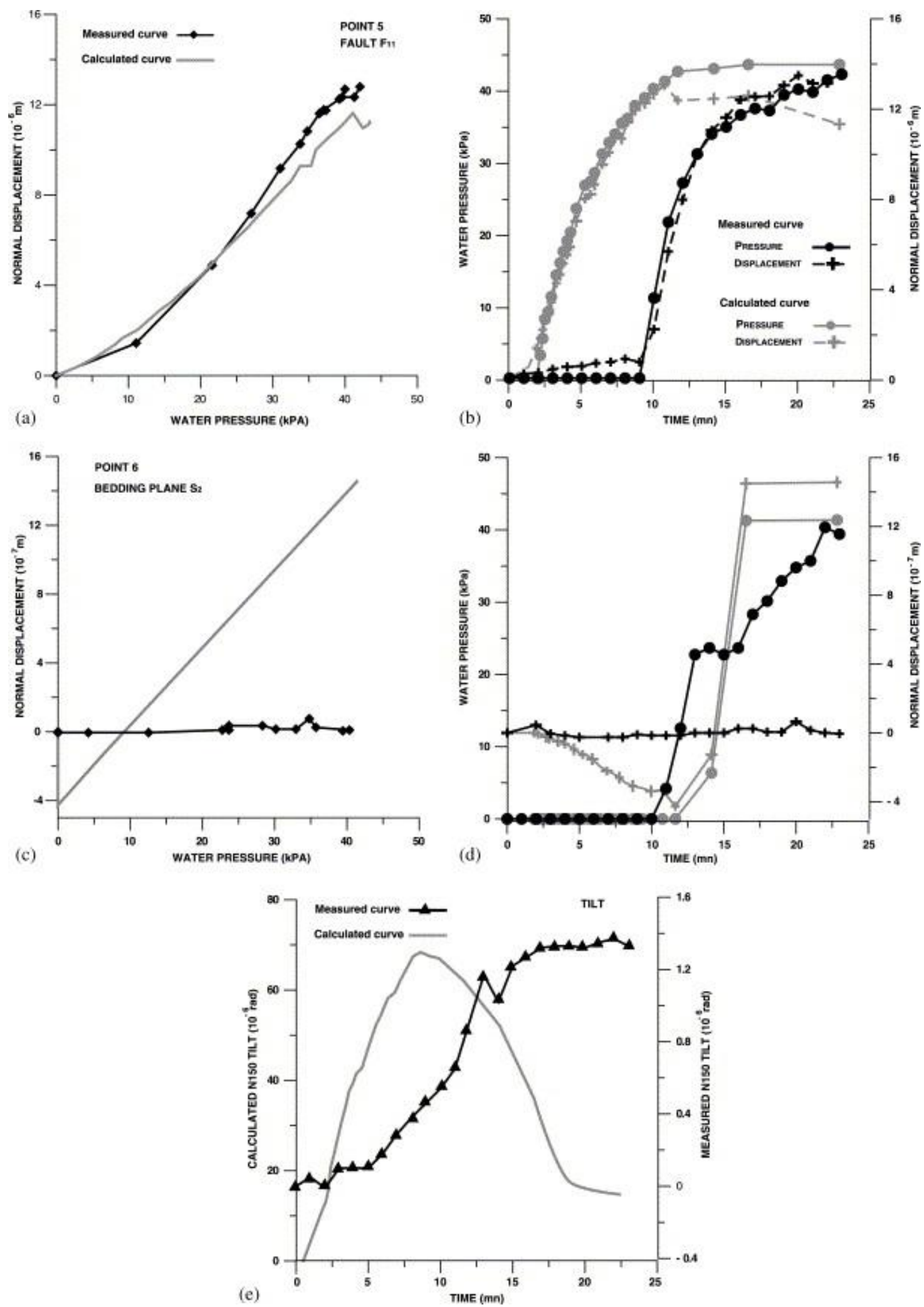

Fig. 7. Reference case of hydromechanical modelling. (a) Normal displacement versus water pressure at point 5 of fault F11. (b) Normal displacement and water pressure versus time at point 5 of fault F11. (c) Normal displacement versus water pressure at point 6 of bedding plane S2. (d) Normal displacement and water pressure versus time at point 6 of bedding plane

S2. (e) N150 tilt versus time (left vertical axis corresponds to calculated N150 tilt-right vertical axis corresponds to measured N150 tilt). 
A significant deviation is observed in the calculated time response of the fault, which is a factor of 3 shorter than the measured time response (Fig. 7b). This can be explained by (1) an overestimation of the fault hydraulic aperture, or (2) a 3D effect linked to the sequence of hydraulic loading. In fact, in situ experiments displayed a $30 \%$ variation of hydraulic apertures not represented in the simple cubic law within the UDEC model. Hydraulic loading is performed by a closing of a water-gate about $12 \mathrm{~m}$ downstream from the chosen cross section (Fig. 2c). After the closure, a transient nonlinear gradient propagation from the watergate to the measuring point can induce a different time lag compared to the simulated vertical pressure rise from the base of the model. For the bedding plane (Fig. 7d), the time lag between calculated and measured responses is much smaller. The shape of the calculated response is very similar to the measured one for the fault. For the bedding plane, the calculated response displays two periods. In the early times, from 0 to $12 \mathrm{~min}$, there occurs a negative displacement variation corresponding to a closure of the plane while there is no pressure in the discontinuity. This period corresponds to the pressure-displacement rise within the fault. Closure of the bedding plane can thus be explained by a normal stress increase in the discontinuity linked to the hydromechanical opening of the fault. After $12 \mathrm{~min}$, there is an increase in displacement values that correlate with the pressure rise within the bedding plane.

Calculated and measured tilt curves look very different. Both present two periods: an early time positive rise, during which the calculated deformation rate is a factor 1.5 higher that the measured one, and a second period of negative (calculated) or null (measurement) variation of measured tilt. Nevertheless, the simulation can help in explaining the tilt response. In the early times $(0-10 \mathrm{mn}$ in Fig. 7), there is a positive rise that corresponds to a rotation towards the right side of the modeled cross section (which is the interior of the slope, as can be seen on Fig. 6). This rotation is correlated with a calculated pressure rise to steady state that occurs only within the vertical faults. The opening of the vertical faults and the closing of bedding planes in the pressurized area cause the swelling of the base of the free surface of the rock mass (between 0 and $6 \mathrm{~m}$ elevation) and the sagging at the top of the free surface of the rock mass (above $6 \mathrm{~m}$ elevation). This sagging explains the rotation of the upper part of the slope. After 10 min of time, there is a negative tilt variation that corresponds to a rotation towards the free surface of the rock mass. This rotation is correlated with a pressure rise inside the bedding planes while it is at steady state inside the vertical faults. As a consequence, deformation is mainly characterized by the bedding plane openings. At the upper part of the slope, it creates a resorption of the early sagging effect, and the negative rise is not observed on the tilt row data. This is explained by the fact that the deformation of bedding planes was overestimated, for two main reasons: (1) the bedding plane stiffness chosen for the calculations is much too low; and (2) in the UDEC modeling, hydromechanical effects occur everywhere within the bedding planes. Experimental data clearly show that this is not a realistic solution, because some zones of the planes are not subject to any displacement (point 3 in Fig. 4). This overestimation of coupled effects within the bedding planes certainly explains the magnitude of calculated tilt, which is 70 times higher than the measured one. Nevertheless, this simulation shows the strong influence of the reservoir volume change on surface tilt. Note that the shape of the tilt curve is directly linked to the dual-permeability behavior of the aquifer, which induces two successive loading effects in two different zones of the rock mass. 


\subsubsection{Effect of stiffness of discontinuities}

The stiffness of bedding planes strongly affects the pressure/normal displacement relation both for fault F11 and for bedding plane S2 (tests 5, 6, and 7 in Figs. 8a and d). The results show that if the normal stiffness of the bedding plane is above $20 \mathrm{GPa} / \mathrm{m}$, the opening of the fault is reduced by a factor of 2-3 during the pressure rise (Fig. 8a). A variation in initial fault stiffness from maximum to average values also reduces the opening of the fault by a factor of 3, but it does not influence the bedding plane response (test 8, and 9 in Figs. 8a and d). A kn1 of $500 \mathrm{GPa} / \mathrm{m}$ allocated to the bedding plane is necessary to capture the low normal displacement of this one (test 7 in Fig. 8d). This value can be considered as realistic for a natural bedding plane in fresh calcareous rocks compared to laboratory values [16].
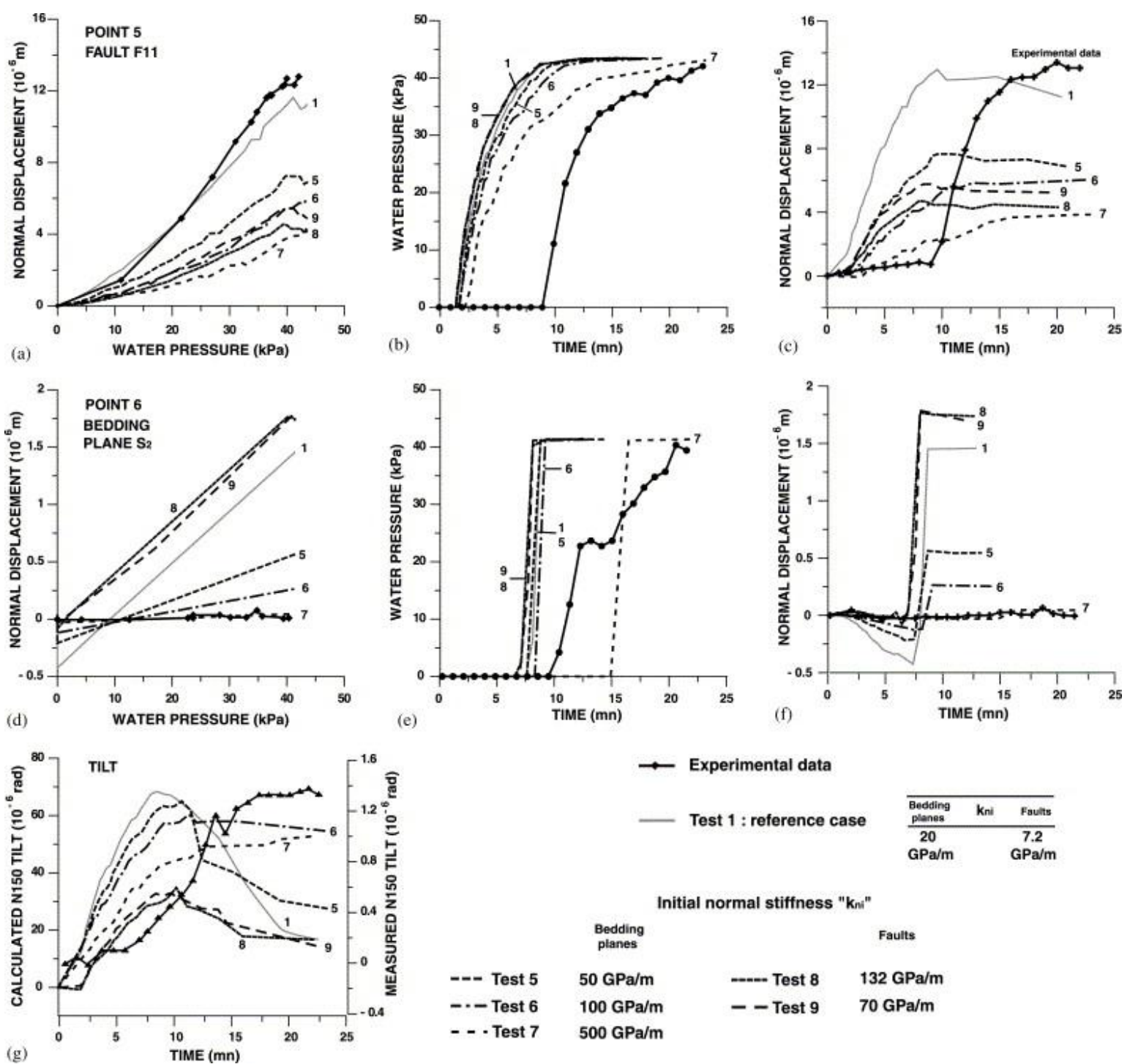

Fig. 8. Sensitivity analysis to discontinuity initial stiffness change. (a) Normal displacement versus water pressure at point 5 of fault F11. (b) Water pressure versus time at point 5 of fault F11. (c) Normal displacement versus time at point 5 of fault F11. (d) Normal displacement versus water pressure at point 6 of bedding plane $S 2$. (e) Water pressure versus time at point 6 of bedding plane S2. (f) Normal displacement versus time at point 6 of bedding plane S2. ( $g$ ) N150 tilt versus time (left vertical axis corresponds to calculated N150 tilt and right vertical axis corresponds to measured N150 tilt). 
Stiffness has no effect on calculated time responses of water pressure for normal displacements that do not agree well with the experimental responses (Figs. 8b, c, e and f). The discrepancy is significant in the fault, for which all the curves look roughly similar to curves of the reference case. It is also about the same for bedding planes, where the time lag is approximated except for test 7 , for which the calculated pressure increase is delayed compared with the measured one (Fig. 8e). This is explained by the very small opening of the bedding plane under pressure rise compared to the other tests (Fig. 8f). Thus, the hydraulic conductivity of the bedding plane remains much lower than in the other tests.

Calculated surface deformations in each test did not agree well with the measured ones. Nevertheless, it clearly appears that the magnitude of N150 tilt is intimately dependent on stiffness of discontinuities. Particularly, a stiffness of $132 \mathrm{GPa} / \mathrm{m}$ (test 8 in Fig. 8g) of the fault allows an approximation of the measured tilt amplitude, even if the calculated magnitude remains 20 times higher than measured one. Test 7 results displays a tilt signal with no negative variation after $10 \mathrm{~min}$ that looks close to the shape of the experimental signal, even if, the calculated amplitude is also much too high.

Results shown in Fig. 8 highlight further the significant sensitivity of hydromechanical couplings in the rock mass to stiffness changes in discontinuities. Notably, the stiffness of bedding planes strongly affects the normal displacement of faults and the surface tilt signal. Initial normal stiffness of fault inferred from in situ measurements appears to have the best agreement with the calibrated pressure/normal displacement relation within faults. Concerning the bedding planes, results of numerical study show that the back-calculated normal stiffness that best fits field measurements is $500 \mathrm{GPa} / \mathrm{m}$, which is up a factor of 25 from the value obtained by laboratory tests. This is likely caused by a scale effect linked to unrepresentative sampling of the bedding plane surface asperities between tested areas in core samples and actual areas of in situ bedding planes.

\subsubsection{Effect of hydraulic apertures of discontinuities}

Initial hydraulic aperture values for discontinuities have a minor effect on the magnitude and shape of pressures/normal displacements curves, both for faults and bedding planes and for the surface deformations (Figs. 9a, d and g). It clearly shows that a great contrast in initial hydraulic apertures between faults and bedding planes shifts the pressure-time and the normal displacement-time bedding planes curves by a factor of 1-2 along the time axis (Figs. 9e and $\mathrm{f}$, test 4). Moreover, results from Test 4 show that the inflexion part separating the two slightly nonlinear slopes of fault pressure and normal displacement curves (Fig. 9b and c) is strongly influenced by the bedding plane closures during the pressure increase in faults. For the magnitude of bedding plane closure, the opening of fault in the inflexion part occurs with a different magnitude, according to the contrast in hydraulic apertures between discontinuities. The more significant the contrast in hydraulic aperture, the higher the magnitude of fault opening is (test 4 in Fig. 9c). Inversely, the lower the contrast in hydraulic apertures, the lower the magnitudes of fault opening (test 3 in Fig. 9c). This implies that the fault normal displacement is dependent on pressure increase and on displacement of the surrounding less permeable discontinuities. 

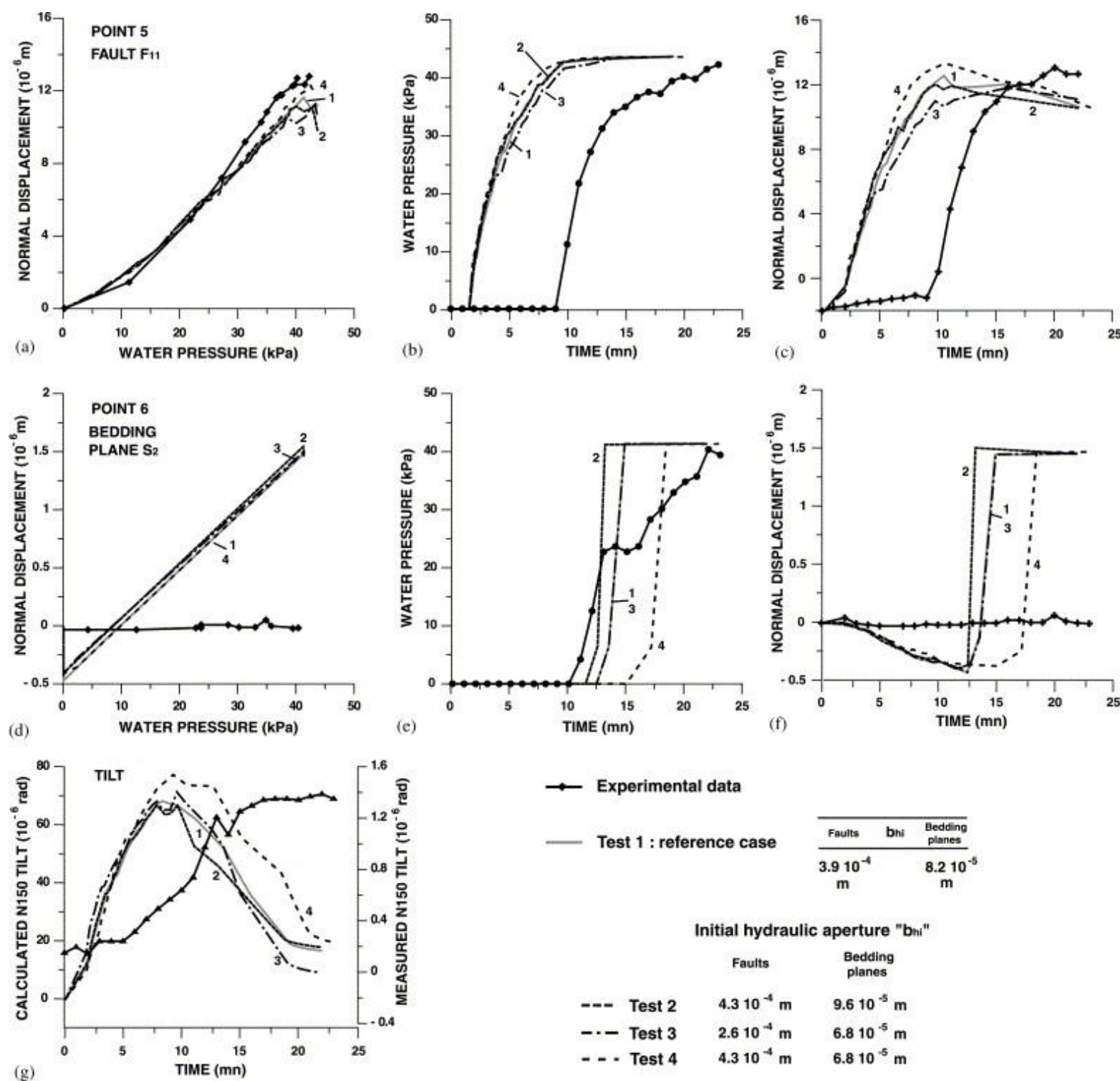

Fig. 9. Sensitivity analysis to discontinuity initial hydraulic aperture change. (a) Normal displacement versus water pressure at point 5 of fault F11. (b) Water pressure versus time at point 5 of fault F11. (c) Normal displacement versus time at point 5 of fault F11. (d) Normal displacement versus water pressure at point 6 of bedding plane S2. (e) Water pressure versus time at point 6 of bedding plane S2. (f) Normal displacement versus time at point 6 of bedding plane S2. $(g$ ) N150 tilt versus time (left vertical axis corresponds to calculated N150 tilt and right vertical axis corresponds to measured N150 tilt).

A change in hydraulic aperture does not cause a significant change in surface tilt deformations. However, the magnitude is higher when the contrast in hydraulic apertures is higher (Fig. 9g, test 4).

\subsubsection{Effect of deformation modulus of rock matrix}

Young's moduli variations (between 50 and $90 \mathrm{GPa}$ ) have no significant influence on the magnitude and shape of pressures and normal displacements curves for discontinuities, or on surface deformations (Fig. 10). 

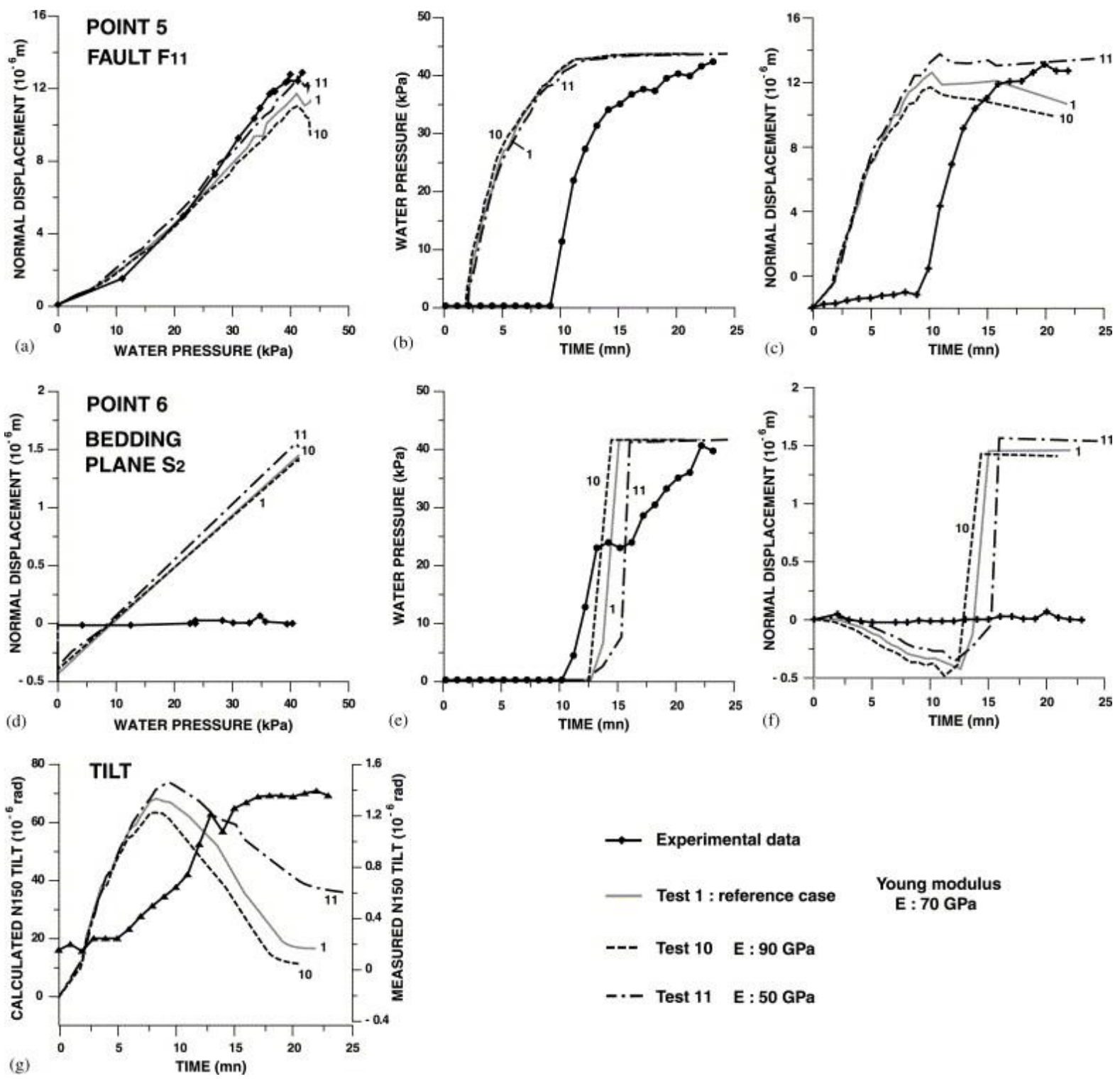

Fig. 10. Sensitivity analysis to Young's modulus change in rock matrix (a) Normal displacement versus water pressure at point 5 of fault F11. (b) Water pressure versus time at point 5 of fault F11. (c) Normal displacement versus time at point 5 of fault F11. (d) Normal displacement versus water pressure at point 6 of bedding plane $S 2$. (e) Water pressure versus time at point 6 of bedding plane S2. (f) Normal displacement versus time at point 6 of bedding plane S2. (g) N150 tilt versus time (left vertical axis corresponds to calculated N150 tilt and right vertical axis corresponds to measured N150 tilt).

\section{Discussion}

\subsection{Nonuniqueness of the solution and discrepancy between models and experiments}

The sensitivity study clearly shows that, at the scale of the rock mass, the calibration is difficult to perform simultaneously at the three measuring points, which causes certain nonuniqueness in the model solution. In fact, if we define the best-fit case as the calculated 
solution that gives simultaneously the closest numerical response to the experimental response measured at all 3 points, tests 1 and 7 can be chosen with the following model resolutions:

- A 5-46\% maximum discrepancy between calculated and measured pressure/normal displacement curves at point 5 on fault F11. Test 1 best fits the fault response, whereas test 7 displays a $46 \%$ discrepancy. Nevertheless, such a discrepancy is far below the differences between experimental responses of faults, which range between $4.5 \times 10-7$ and $2.25 \times 10-4 \mathrm{~m}$ (Fig. 4). The calculated curve is, for example, very close to the experimental curve at point 1 (Fig. 4 and Fig. 5), which is submitted to a similar effective stress to that of point 5 (Table 1).

- A 5-76\% maximum discrepancy between calculated and measured pressure/normal displacement curves at point 6 on bedding plane S2. Test 7 best fits the bedding plane response, whereas test 1 displays a $76 \%$ discrepancy.

- A 94\% maximum discrepancy between calculated and measured tilt curves at point C. The calculated and experimental surface deformation rates look similar, but both tests displayed solutions with results diverging far from the experimental data.

The modeling procedure shows that the hydromechanical behavior inferred from measurements can be approached with a poor-to-medium discrepancy for a high-normalstiffness contrast between bedding planes and faults.

\subsection{Limitation and back analysis of the adopted model parameterization}

At point 3 in Fig. 4, raw experimental data display no displacement variations, whereas there is a pressure rise within the discontinuity. The model is unable to predict no-displacement behaviors within zones of bedding planes. Two possible hypotheses could account for the insufficient effective stress variation at the monitoring point (1) an increase in total normal stress, or (2) an insufficient pressure-rise effect within the discontinuity. The first hypothesis is well formulated in the adopted model formulation. In fact, the coupled analysis performed displays a total stress increase that induces closure of the related bedding plane (Fig. 7d). This closing does not prevent the discontinuity from opening when there is a pressure rise, and signifies that insufficient effective stress variation could be better explained by the second hypothesis. The so-called insufficient effect of pressure rise has been experimentally observed at the laboratory scale and physically linked to the discontinuity morphology [47] and [53]. The effective stress applied to a very rough discontinuity can be described by Eq. (3), in which it clearly appears that a high-pressure rise will have only a slight effect on the mechanical displacement if there is minimal penetration of water between the two surfaces of the discontinuity. Because the Sc parameter is not taken into account in the adopted modeling, pressure rise is applied to the entire surface planes and the displacement generated throughout the discontinuity is much overestimated.

The static modeling is not able to restore pressure and displacement oscillations within the discontinuities. Note that these behaviors are predominant within the low-permeability bedding planes. Similar behavior has been observed in situ in some slug test raw data [54] and in laboratory flow experiments through single discontinuities [30]. Such a behavior is usually explained by the rugosity effect of discontinuity surfaces, which results in a noncylindrical flow. Witherspoon et al. [31] developed a modified cubic law that integrates a friction factor " $\mathrm{f}$ " to account for the roughness of the fracture surface. This modification enables a good description of the nonlinear discontinuity's behavior, but it cannot simulate the oscillations. 
Surface tilt deformation was not well represented by numerical results. Modeling captures the experimental curve shape, but strongly overestimates the tilt magnitude, causing to a poor model solution for representing the hydromechanical behavior of the bedding planes. The main result is that tilt variations come from the convolution of mechanical displacements spread over all the discontinuities of the network. More precisely, differential pressure loading, first within the high permeable discontinuities and then within the remaining low permeable ones, consisted of two successive periods on the tilt curves. This result accords well with studies at others scales that enabled imaging of deep discontinuities resulting from hydromechanical behavior's influence on the subsurface tilt [55].

\subsection{Time response of the discontinuity network}

According to the measured results, a time lag occurs between the time when pressure increases and discontinuity opens, and, inversely, when pressure decreases and discontinuity closes. The same effect is observed for surface-tilt-deformation changes associated with fluid pressure changes. Field observations illustrated well this phenomenon, notably when pressure is stable after hydraulic loading over a 23 -min period. The rock mass deformation continues in discontinuities, in the rock matrix, and on the surface whereas, fluid pressures are stable. This implies that the elastic deformation at a given point of the rock mass may be caused by a local pressure change occurring at an other point a distance away from this one. Such timedependent behavior has been observed for time intervals of some minutes to several hours, and reported in [3], [24], [29], [40], [55] and [56]. The delay between deformation and pressure change has been interpreted as a "distant dilatancy effect", linked to the elastic behavior of the system in response to local pressure perturbation [24]. Alm [40] specified that if fractures and intact rock matrix were viscous and subjected to long-term pressurization, fracture stiffness and hydraulic apertures could be different, because of the time dependent deformation.

\section{Conclusion}

Simultaneous hydraulic and mechanical measurements showed highly variable interdependant hydromechanical responses within a well-connected discontinuities network. From a pressureversus-normal displacement curve analysis, stiffness of single discontinuities can be estimated using a nonlinear function between effective normal stress and normal displacement. It appears that calculated curves only fit the beginning of the experimental pressure-normal displacement curves when pressure rising within the discontinuity is small enough. When pressure rises, the other well-connected surrounding discontinuities are affected, and the hydromechanical response of the tested discontinuity is strongly constrained by boundary conditions. This means that the mechanical parameters of single discontinuities must be deduced from the beginning of in situ pressure-normal displacement curves.

Modeling showed that the mechanical opening of major flow-conducting discontinuities is affected by the stiffness of surrounding less permeable discontinuities. Those discontinuities with a large initial hydraulic conductivity were more sensitive to small changes in effective normal stress than discontinuities with a small initial hydraulic conductivity. A two-parallelplates model with a hyperbolic stress-displacement relation was in good agreement with field behavior. The highly nonlinear and oscillatory behavior of pressure-displacement responses within low-permeable discontinuities show that in some zones of a discontinuity network, the 
same simple model with quasi-static solutions does not match the hydromechanical response of discontinuities.

A more appropriate discrete representation of hydromechanical behavior of a well-connected fractured reservoir would necessary rely on the restoration of complex behavior (like channelling and water compressibility effects) for low permeable discontinuities that represent almost $96 \%$ of the reservoir network.

\section{Acknowledgments}

Constructive comments by Dr. Chin-Fu Tsang, Dr. Jonny Rutqvist (Lawrence Berkeley National Laboratory), Dr. Mountaka Souley, Dr. Medhi Ghoreychi (INERIS) and Dr. Christopher Wibberley (Geosciences Azur) are much appreciated. This research was funded by the FORPRO 2004/05 A and INERIS-BCRD-DRS2 programs. Publication no. 678 of Géosciences Azur.

\section{References}

[1] F.O. Jones, A laboratory study of the effects of confining pressure on fracture flow and storage in carbonate rocks, J Pet Technol 27 (1975), pp. 21-27.

[2] M.D. Zoback and J.D. Byerlee, Permeability and effective stress, AAPG Bull 59 (1975), pp. 154-158.

[3] Gale J. A numerical, field and laboratory study of flow in rock with deformable fractures. PhD Thesis, University of California, Berkeley, 1975, 143p.

[4] Goodman RE. Deformability of joints. In: Proceedings Of the Symposium on Determination of the In-situ Modulus of deformation of rock, vol. 477. 2-7 February, Denver, Colorado. AsTm Spec Tech Publication, 1970.p. 174-96.

[5] R.E. Goodman, Methods of geological engineering in discontinuous rocks, West Publishing Company, Goodman, New York (1976).

[6] Y.W. Tsang and P.A. Witherspoon, Hydromechanical behavior of a deformable rock fracture subject to normal stress, J Geophys Res 86 (1981), pp. 9287-9298.

[7] S.C. Bandis, A.C. Lumsden and N. Barton, Fundamentals of rock joint deformation, Int J Rock Min Sci Geomech Abstr 20 (1983), pp. 249-268.

[8] K.G. Raven and J.E. Gale, Water flow in a natural rock fracture as a function of stress and sample size, Int J Rock Mech Min Sci Geomech Abstr 22 (1985), pp. 251-261.

[9] Gentier S. Morphologie et comportement mécanique d'une fracture naturelle dans un granite sous contrainte normale. PhD Thesis, University of Orléans, 1986, 637p.

[10] Pyrak-Nolte L, Myer LJ, Cook NGW, Witherspoon PA. Hydraulic and mechanical properties of natural fractures in low permeability rock. In: Herget G, Vongpaisal S, editors. 
Proceedings of the Sixth Congrress on International Society of Rock Mechanics, vol. 1. Montréal. Balkema: Rotterdam; 1987. p. 225-31.

[11] A. Makurat, N. Barton and N.S. Rad, Joint conductivity variation due to normal and shear deformation In: N. Barton and O. Stephansson, Editors, Rock Joints, Balkema, Rotterdam (1990), pp. 535-540.

[12] Sotoudeh A. Etude expérimentale et modélisation du couplage hydromécanique de joints rocheux. PhD Thesis, University of Lille, France, 1995.

[13] Goodman RE. The mechanical properties of joints. In: Proceedings of the third International Congress International Society of Rock Mechanics Denver, Colorado. National Academy of Sciences, Washington, DC: 1974. vol. 1, p. 127-40.

[14] C.E. Neuzil and J.V. Tracy, Flow through fractures, Water Resour Res 17 (1981), pp. 191-199.

[15] Cundall PA, Hart RD. Analysis of Block Test No. 1 Inelastic Rock Mass Behavior: Phase 2-A Characterization of Joint Behavior (Final report). Itasca Consulting Group report, Rockwell Hanford Operations, Subcontract SA-957, 1984.

[16] N.R. Barton, S. Bandis and K. Bakhtar, Strength, deformation, and conductivity coupling of rock joints, Rock Mech Min Sci Geomech 22 (1985), pp. 121-140.

[17] Lemos JV. A distinct element model for dynamic analysis of jointed rock with application to dam foundations and fault motion. PhD Thesis, University of Minnesota, 1987.

[18] Rutqvist J. Coupled stress-flow properties of rock joints from hydraulic field testing. PhD Thesis, Royal Institute of Technology, Sweden, 1995.

[19] G. Duveau, M. Sibai, X. Dunat, F. Skoczylas and J.P. Henry, Modélisation du comportement hydromécanique d'un joint rocheux sous contrainte normale, Revue française de géotechnique 81 (1997), pp. 41-51.

[20] J. Rutqvist and O. Stephansson, The role of hydromechanical coupling in fractured rock engineering, Hydrogeol J 11 (2003), pp. 7-40.

[21] J. Rutqvist, Determination of hydraulic normal stiffness of fractures in hard rock from well testing, Int J Rock Mech Min Sci Geomech Abstr 32 (1995), pp. 513-523.

[22] J. Rutqvist, J. Noorishad, C.F. Tsang and O. Stephansson, Determination of fracture storativity in hard rocks using high-pressure injection testing, Water Resour Res 34 (1998), pp. 2551-2560.

[23] C.F. Tsang, Linking thermal, hydrological, and mechanical processes fractured rocks, Annu Rev Earth Planet Sci 27 (1999), pp. 359-384.

[24] F.H. Cornet, L. Li, J.P. Hulin, I. Ippolito and P. Kurowski, The hydromechanical behaviour of a fracture an in situ experimental case study, Int J Rock Min Sci Geomech Abstr 40 (2003), pp. 1257-1270. 
[25] T.W. Doe and G.E. Korbin, A comparison of hydraulic fracturing and hydraulic jacking stress measurements, 28th US Symposium on Rock Mechanics, Tucson (1987).

[26] R. Jung, Hydraulic in situ investigation of an artificial fracture in the Falkenberg granite, Int J Rock Min Sci Geomech Abstr 26 (1989), pp. 301-308.

[27] Gertsch LS. Changes in in situ rock joint flow characteristics caused by mechanical displacement. In: Hustrulid WA, Johnson CA, editors. Rocks mechanics contributions and challenges, 31st US Symp. Golden, Colorado, A.A. Balkema, 1990. p. 363-370.

[28] C.D. Martin, C.C. Davison and E.T. Kozak, Characterizing normal stiffness and hydraulic conductivity of a major shear zone in granite In: N. Barton and O. Stephansson, Editors, Rock Joints, Balkema, Rotterdam (1990), pp. 549-556.

[29] L.R. Myer, Hydromechanical and seismic properties of fractures In: W. Wittke, Editors, ProcEedings of the Seventh International Congrress on Rock Mechanics. Aagen, Germany, Balkema, Rotterdam (1991), pp. 397-404.

[30] Louis, CL. A study of Groundwater Flow in Jointed Rock and Its Influence on the stability of Rock Masses Imperial College, Rock Mechanics Research Report No. 10, 1969.

[31] P.A. Witherspoon, J.S.Y. Wang, K. Iwai and J.E. Gale, Validity of cubic law for fluid flow in a deformable rock fracture, Water Resour Res 16 (1980), pp. 1016-1024.

[32] R. Tse and D.M. Cruden, Estimating joint roughness coefficients, Int J Rock Mech Min Sci Geomech Abstr 32 (1979), pp. 513-523.

[33] Fénart P. Caractérisation du comportement hydromécanique des massifs rocheux fissurés. PhD Thesis, University of Montpellier II, 2002. 308p.

[34] Guglielmi Y. Apport de la mesure des couplages hydromécaniques à la connaissance hydrogéologique des réservoirs fissurés: approche sur site expérimental. Second Thesis, University of Franche-Comté, 1999. 153p.

[35] Y. Guglielmi and J. Mudry, Quantitative measurements of channel-block hydraulic interactions by experimental saturation of a large, natural, fissured rock mass, Ground Water 39 (2001), pp. 696-701.

[36] H.H. Cooper, J.D. Bredehoeft and I.S. Papadopulos, Response of a finite-diameter well to an instantaneous charge of water, Water Resour Res 3 (1967), pp. 263-269.

[37] J.H. Black, The interpretation of slug tests in fissured rocks, Q J Eng Geol London 18 (1985), pp. 161-171.

[38] J.J. Butler Jr., C. McElwee and W. Liu, Improving the quality of parameter estimates obtained from slug tests, Ground Water 34 (1996), pp. 480-490.

[39] A.C. Gringarten and H.J. Ramey, Unsteady-state pressure distributions created by a well with a single horizontal fracture, partial penetration, or restricted entry, Soc Petrol Eng J 14 (1974), pp. 413-426. 
[40] Alm P. Hydro-mechanical behavior of a pressurized single fracture: an in situ experiment. PhD Thesis, Chalmers University, Sweden, 1999. 102p.

[41] K. Evans and F. Wyatt, Water table effects on the measurement of earth strain, Tectonophysics 108 (1984), pp. 323-337.

[42] Kumpel HJ. Model calculations for rainfall induced tilt and strain anomalies. In: Vieira $\mathrm{R}$, editor. Proceedings of the tenth international symposium on earth tides. Madrid, 1986. p. 889-901.

[43] M. Zadro and C. Braitenberg, Measurements and interpretation of tilt-strain gauges in seismically active areas, Earth-Sci Rev 47 (1999), pp. 151-187.

[44] D.W. Vasco, K. Karasaki and O. Nakagome, Monitoring production using surface deformation the Hijori test site and Okuaizu geothermal field, Japan, Geothermics 31 (2002), pp. 303-342.

[45] M. Fabian and H.J. Kümpel, Poroelasticity observations of anomalous near surface tilt induced by ground water pumping, J Hydrol 281 (2003), pp. 187-205.

[46] J.P. Henry and M. Sibai, Couplage hydromécanique dans les joints rocheux sous sollicitations normales proposition de modélisation et comparaison avec l'expérience, Expériment Calcul Génie Civil (1997), pp. 47-54.

[47] M. Sibai, M. Haji Sotoudeh and J.P. Henry, Etude expérimentale du couplage hydromécanique de joints rocheux, Rev Fr Géotech 81 (1997), pp. 33-39.

[48] N. Rode, F. Homand-Etienne, R. Hadadou and V. Soukatchoff, Mechanical behaviour of joints in cliffs and open pits In: Barton and Stephanson, Editors, Rock joints, Balkema, Rotterdam (1990), pp. 27-33.

[49] Cundall PA. A generalized distinct element program for modelling jointed rock, Peter Cundall Associates, US Army, European Research office, London Report, PCAR-1-80, 1980.

[50] Cundall PA, Hart RD. Development of generalized 2-D and 3-D distinct element programs for modeling jointed rock. Itasca Consulting Group; US Army Corps of Engineers, Misc. Paper SL-85-1, 1985.

[51] Cundall PA. Numerical modelling of jointed and faulted rock. In: Mechanics of Jointed and Faulted Rock. Rotterdam: A.A. Balkema; 1990. p. 11-18.

[52] N.C. Last and T.R. Harper, Response of fractured rock subject to fluid injection, Part I development of a numerical model, Tectonophysics 172 (1990), pp. 1-31.

[53] R.W. Zimmerman, D.W. Chen, J.C.S. Long and N.G.W. Cook, Hydromechanical coupling between stress, stiffness and hydraulic conductivity of rock joints and fractures In: N. Barton and O. Stephansson, Editors, Rock Joints Proceedings International Symposium, Leon, Balkema, Norway (1990). 
[54] C.D. McElwee and M. Zenner, A nonlinear model for analysis of slug-test data, Water Resour Res 34 (1998), pp. 55-66.

[55] W. Castillo, S. Hunter, P. Harben, C. Wright, R. Conant and E. Davis, Deep hydraulic fracture imaging recent advances in tiltmeter technologies, Int J Rock Min Sci Geomech Abstr 34 (1997) Paper No 47.

[56] Pine RJ. Rock joint and rock mass behaviour during pressurized hydraulic injections. PhD Thesis, Camborne School of Mines/Council for National Academic awards, 1986. 